Article

\title{
Characterization and Determination of 2-(2-Phenylethyl)chromones in Agarwood by GC-MS
}

\author{
Wen-Li Mei ${ }^{1,2}$, De-Lan Yang ${ }^{1,2}$, Hao Wang ${ }^{1,2}$, Jin-Ling Yang ${ }^{1,2}$, Yan-Bo Zeng ${ }^{1,2}$, \\ Zhi-Kai Guo ${ }^{1,2}$, Wen-Hua Dong ${ }^{1,2}$, Wei $\mathrm{Li}^{1,2}$ and Hao-Fu Dai ${ }^{1,2, *}$
}

1 Key Laboratory of Biology and Genetic Resources of Tropical Crops,

Ministry of Agriculture, Institute of Tropical Bioscience and Biotechnology,

Chinese Academy of Tropical Agricultural Sciences, Haikou 571101, China

2 Hainan Key Laboratory for Research and Development of Natural Product from Li Folk Medicine, Haikou 571101, China

* Author to whom correspondence should be addressed; E-Mail: daihaofu@itbb.org.cn;

Tel./Fax: +86-898-6696-1869.

Received: 31 July 2013; in revised form: 19 September 2013 / Accepted: 26 September 2013 /

Published: 8 October 2013

Abstract: Agarwood is the fragrant resinous heartwood obtained from certain trees in the genus Aquilaria belonging to the family Thymelaeaceae. 2-(2-Phenylethyl)chromones and characteristic sesquiterpenes are the main classes of aromatic compounds isolated from agarwood. Although there are many sesquiterpenes, relatively few 2-(2-phenylethyl)chromones have been determined in agarwood by GC-MS. After analysis of the MS spectra of eighteen 2-(2-phenylethyl)chromone derivatives isolated from agarwood and identified by NMR spectroscopy, together with the reported MS data and characteristic of structures of 2-(2-phenylethyl)chromones, the MS characterization, fragmentation patterns and characteristic fragment peaks for the compounds were deduced and a table summarizing MS characterization of 2-(2-phenylethyl)chromones in agarwood is presented. All the 2-(2-phenylethyl)chromones previously reported in agarwood are substituted by methoxy or/and hydroxy groups, except for one compound. Due to the fact they all possess the same basic skeleton (molecular weight: 250) and similar substituent groups (methoxy or hydroxy groups), a formula $(30 m+16 n=M W-250)$ is provided to calculate the number of methoxy $(\mathrm{m})$ or hydroxy $(\mathrm{n})$ groups according to molecular ion peak or molecular weight (MW). We deduced that the characteristic fragmentation behaviors of the 2-(2-phenylethyl)chromones are the cleavages of the $\mathrm{CH}_{2}-\mathrm{CH}_{2}$ bond between chromone moiety and phenyl moiety. Thus, characteristic fragment ions, such as 
$m / z 91\left[\mathrm{C}_{7} \mathrm{H}_{7}\right], 107\left[\mathrm{C}_{7} \mathrm{H}_{6}+\mathrm{OH}\right], 121\left[\mathrm{C}_{7} \mathrm{H}_{6}+\mathrm{OCH}_{3}\right], 137\left[\mathrm{C}_{7} \mathrm{H}_{5}+\mathrm{OH}+\mathrm{OCH}_{3}\right]$ are formed by different substituted benzyl moieties, while characteristic fragment ions such as $\mathrm{m} / \mathrm{z}$ $160\left[\mathrm{C}_{10} \mathrm{H}_{8} \mathrm{O}_{2}\right], 176 \quad\left[\mathrm{C}_{10} \mathrm{H}_{7} \mathrm{O}_{2}+\mathrm{OH}\right], 190 \quad\left[\mathrm{C}_{10} \mathrm{H}_{7} \mathrm{O}_{2}+\mathrm{OCH}_{3}\right], 220 \quad\left[\mathrm{C}_{10} \mathrm{H}_{6} \mathrm{O}_{2}+\mathrm{OCH}_{3} \times 2\right]$ are formed by different substituted chromone moieties. Furthermore, rules regarding to the relationship between the positions of hydroxy or methoxy groups and the relative abundances of benzyl and chromone fragment ions have been deduced. Elucidation of how the positions of hydroxy or methoxy groups affect the relative abundances of benzyl and chromone fragment peaks is also provided. Fifteen unidentified compounds of an artificial agarwood sample analyzed by GC-MS, were preliminary determined as 2-(2-phenylethyl)chromones by analysis of their MS characterization and by comparison of their MS spectra with those of 18 standard compounds or 2-(2-phenylethyl)chromones reported in literature according to the above-mentioned methods and rules. This report will be helpful for the analysis and structural elucidation of 2-(2-phenylethyl)chromones in agarwood by GC-MS, and provides fast and reliable characterization of the quality of agarwood.

Keywords: agarwood; 2-(2-phenylethyl)chromone; fragmentation pattern; GC-MS

\section{Introduction}

Agarwood is a fragrant resinous wood obtained from certain trees in the genus Aquilaria belonging to the family Thymelaeaceae [1,2]. The precious, high-priced, fragrant agarwood, also called chen-xiang in Chinese, gaharu and kalambak in Malaysia, kanankoh and jinkoh in Japan, oudh, eaglewood, agar, ghara, and aloeswood, has been used for centuries as incense in Buddhist, Hindu and Islamic ceremonies [1,2]. It also plays an important role in Chinese Traditional Medicine for use as a sedative and carminative, and to relieve gastric problems, coughs, rheumatism and high fever [3]. The healthy wood of Aquilaria trees is white, soft and without scented resins. It is widely accepted that the dark resinous material of Aquilaria is created as a response to some form of injury to the tree, including natural injuries, such as lightning strikes, animal grazing, insect attacks or microbial invasions, and artificial injuries, such as cutting, nailing, holing, fire, chemical wounding, and deliberate fungi inoculation [2,4-6]. Agarwood formation occurs slowly and infrequently in Nature and the supply of agarwood from wild sources is far less than market demand. Because of its immense value and rarity, indiscriminate cutting of trees and overharvesting in hope of finding the treasured resin has led to the depletion of wild trees [7,8]. Nine Aquilaria species, including A. sinensis, were listed on the IUCN red list as endangered species [9]. Since 2004 all species of Aquilaria have been placed on the Appendix II list of the Convention on International Trade in Endangered Species of Wild Fauna and Flora [1]. Trade in agarwood has intensified in recent years due to demand and commercial value. Prices for agarwood products range greatly from US\$100/kg up to US $\$ 100,000 / \mathrm{kg}$ for different qualities [1]. All sorts of false agarwood have emerged in the market, so the establishment of scientific and reliable methods to evaluate agarwood quality is very important. 
Chemical analyses of agarwood show that its most abundant components are 2-(2-phenylethyl)chromone derivatives (41\%) and other sesquiterpenes (52\%) [2]. 2-(2-Phenylethyl)chromone derivatives of agarwood have been isolated and identified by our previous work [10-13]. Despite the occurrence of many sesquiterpenes, only a few 2-(2-phenylethyl)chromones have been determined by GC-MS for agarwood [14-17]. This paper summarizes MS characterization of 2-(2-phenylethyl)chromones and provides methods to characterize 2-(2-phenylethyl)chromones in agarwood by analysis of their characteristic MS fragmentation patterns and by comparison of their MS spectra with reported ones. This report should be helpful for the analysis and structural elucidation of 2-(2-phenylethyl)chromones in agarwood by GC-MS, and provides a scientific basis for the fast, simple, and sound evaluation of the quality of agarwood.

\section{Results and Discussion}

2-(2-Phenylethyl)chromone derivatives 1-18 were isolated from Chinese agarwood in our laboratory, and their structures identified by NMR analysis [10-13]. By comparison of the MS spectra of 2-(2-phenylethyl)chromones 1-18 (Figure 1), it was determined that these chromones have very similar characteristic mass spectra. A molecular ion peak (in the relative molecular mass range from 250 to 400 , the abundance is usually under $60 \%$ ), together with a fragment base peak, and sometimes also one or two another fragment peaks (abundance of more than 30\%) can be observed, while the abundances of other fragment peaks are mostly less than $10 \%$. The fragment base peak and the main fragment peaks were mostly at $\mathrm{m} / \mathrm{z} 91,121,137,107,160,176,190,220$, etc.

By analyzing the molecular ion peaks and the characteristic fragment ion peaks of compounds 1-18, we deduce that the $\mathrm{CH}_{2}-\mathrm{CH}_{2}$ bond which connects the chromone moiety with the phenyl moiety was cleaved after electron impact (Scheme 1). Thus, the hydroxyl- or methoxy-substituted benzyl moieties provide characteristic ions at $\mathrm{m} / z$ $91\left[\mathrm{C}_{7} \mathrm{H}_{7}\right], 107\left[\mathrm{C}_{7} \mathrm{H}_{6}+\mathrm{OH}\right], 121\left[\mathrm{C}_{7} \mathrm{H}_{6}+\mathrm{OCH}_{3}\right], 137$ $\left[\mathrm{C}_{7} \mathrm{H}_{5}+\mathrm{OH}+\mathrm{OCH}_{3}\right]$, etc.; while the hydroxyl- or methoxy-substituted chromone moieties provide characteristic ions at $m / z \quad 160 \quad\left[\mathrm{C}_{10} \mathrm{H}_{8} \mathrm{O}_{2}\right], \quad 176 \quad\left[\mathrm{C}_{10} \mathrm{H}_{7} \mathrm{O}_{2}+\mathrm{OH}\right], \quad 190 \quad\left[\mathrm{C}_{10} \mathrm{H}_{7} \mathrm{O}_{2}+\mathrm{OCH}_{3}\right], 220$ $\left[\mathrm{C}_{10} \mathrm{H}_{6} \mathrm{O}_{2}+\mathrm{OCH}_{3} \times 2\right]$, etc.

To further verify the above conjecture, we analyzed all the 2-(2-phenylethyl)chromones isolated from agarwood and their MS data, which are listed in Table 1. Except for one compound (No. 32) substituted by acetoxyl group, all the other compounds were found to be substituted by hydroxy or/and methoxy groups. Thus, due to the fact all the 2-(2-phenylethyl)chromones isolated from agarwood share the same basic skeleton (molecular weight: 250) and similar substituent groups (mainly hydroxy and methoxy), the number of methoxy or hydroxy groups can be determined from the molecular ion peak, or molecular weight (MW) through the Formula (1), in which "m" means the number of methoxy groups, and " $n$ " means the number of hydroxyl groups .

$$
30 m+16 n=M W-250
$$


Figure 1. MS spectra of compounds 1-18 and the structures of characteristic fragment ions.

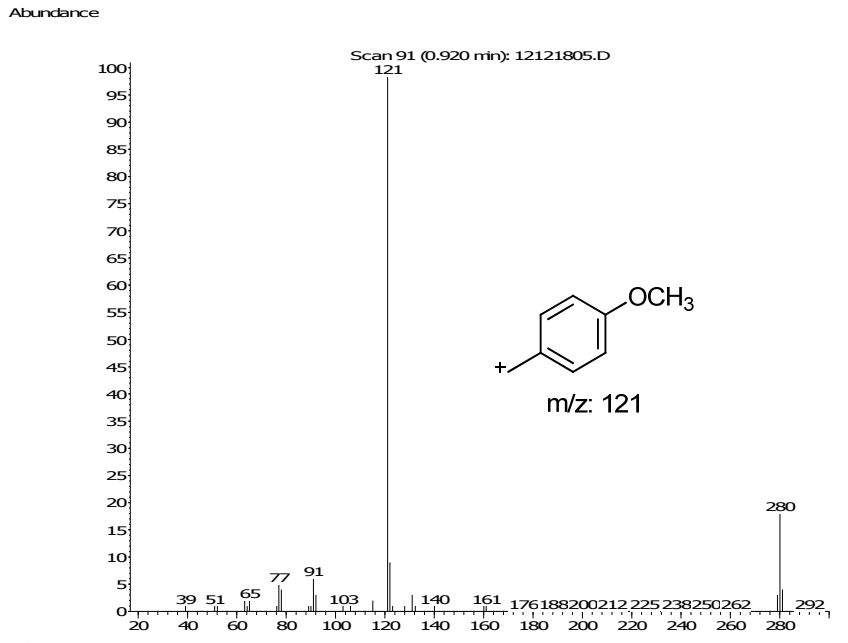

Compound 1

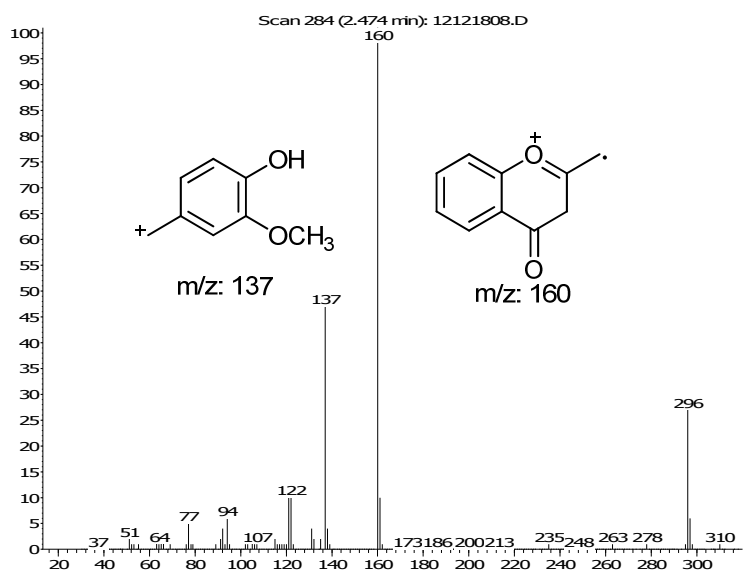

Compound 3
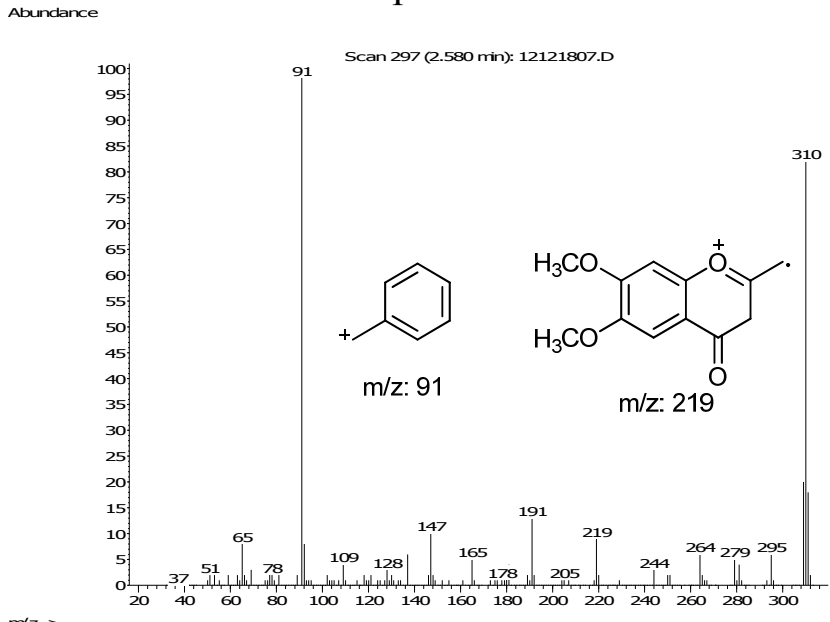

Compound 5

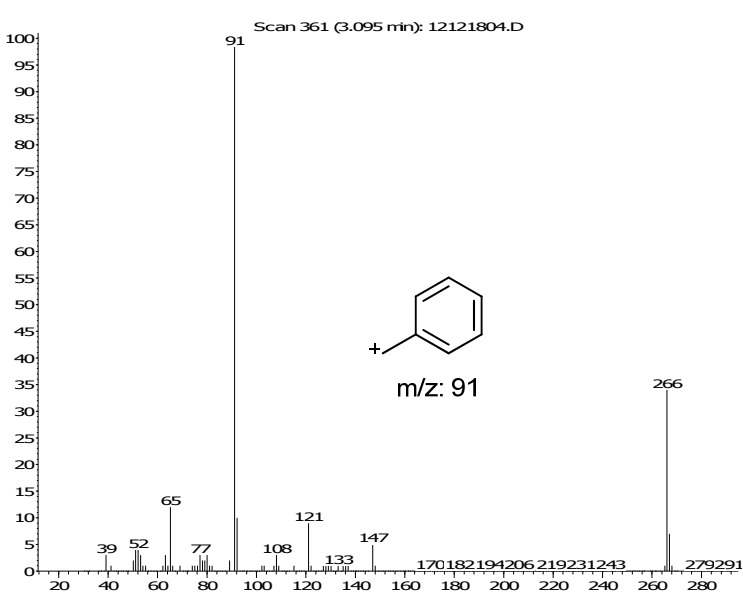

\section{Compound 2}

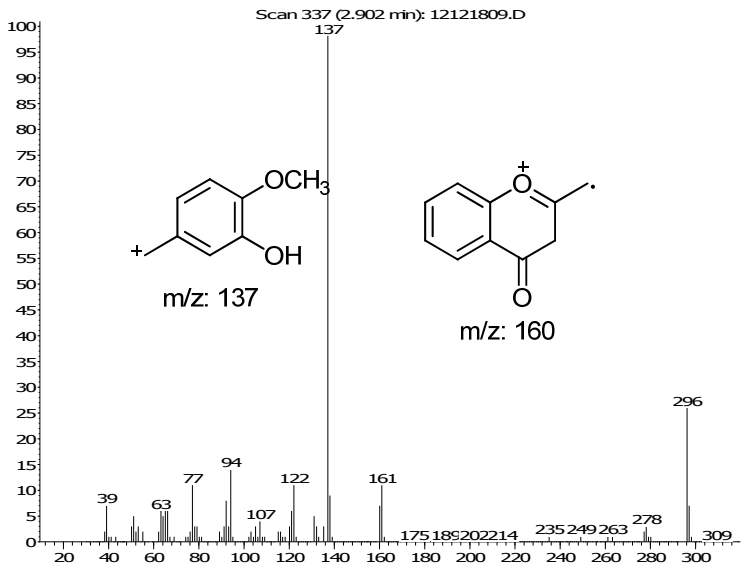

Compound 4

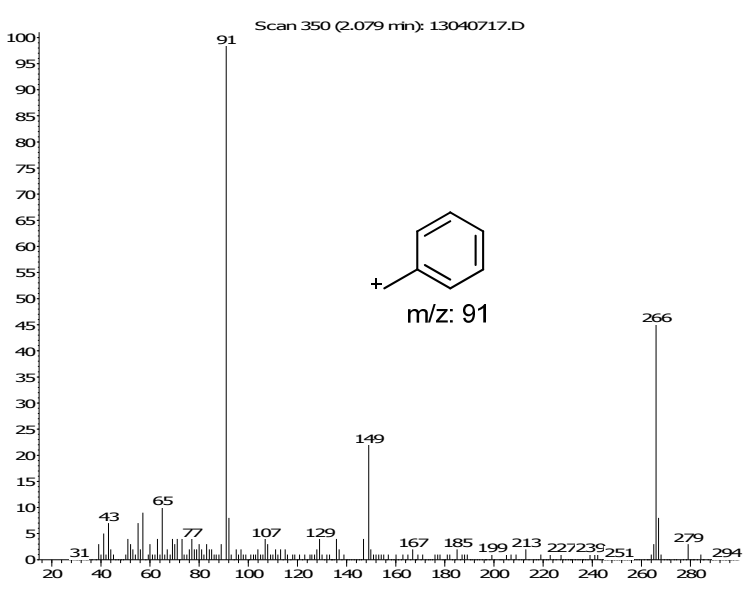

Compound 6 
Figure 1. Cont.

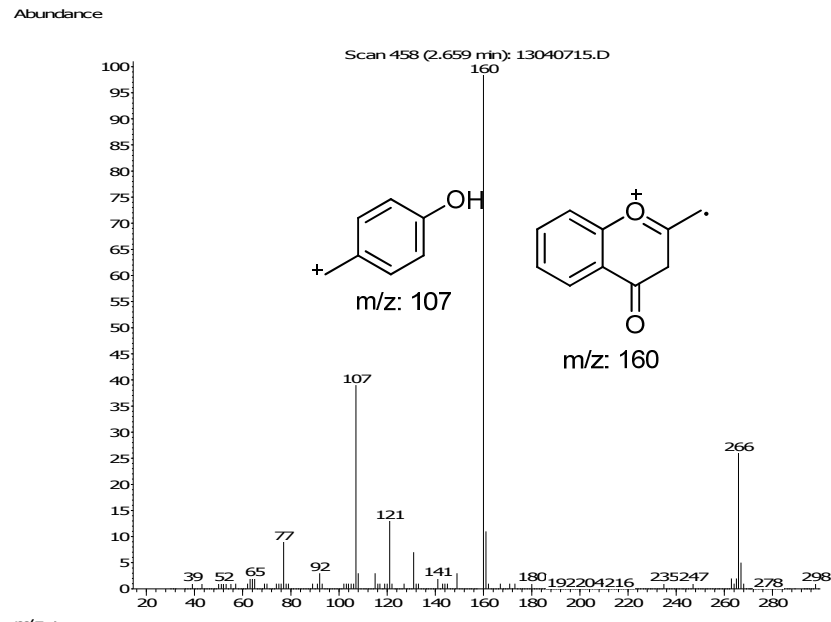

Compound 7

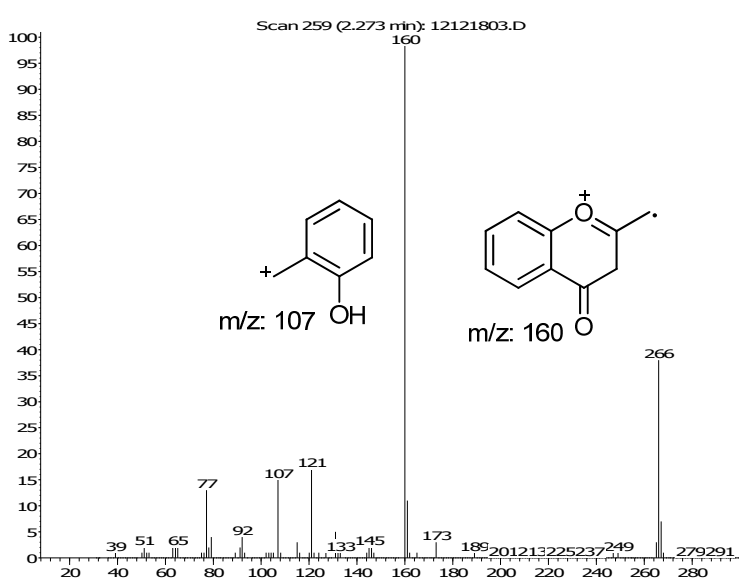

Compound 9

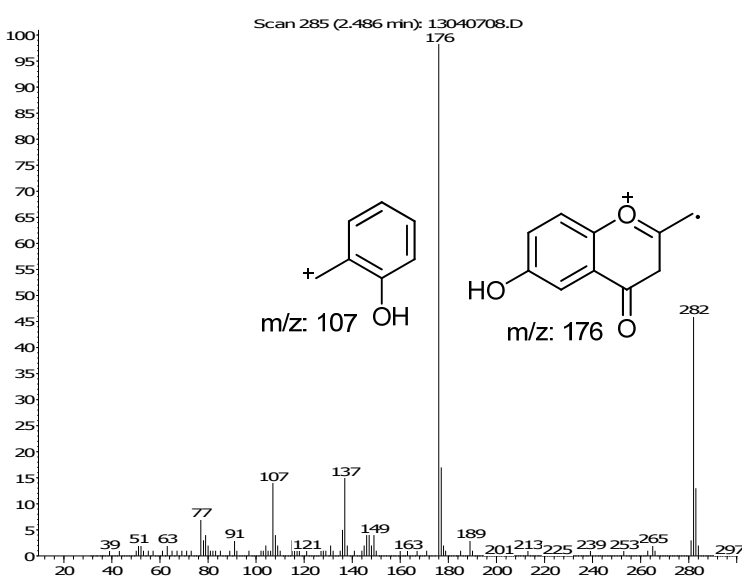

Compound 11

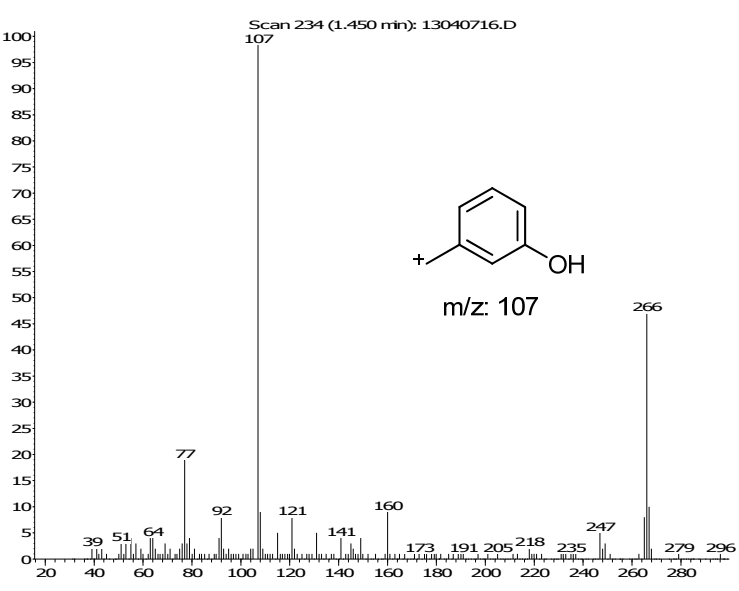

Compound 8

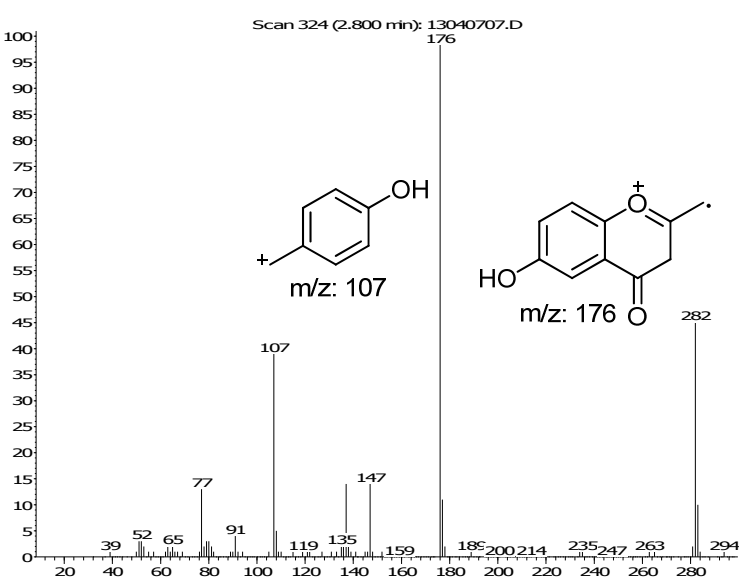

Compound 10

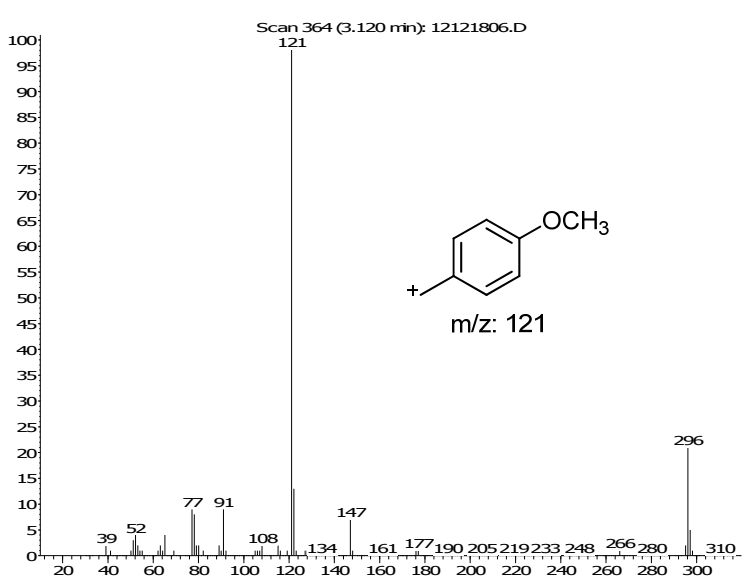

Compound 12 
Figure 1. Cont.

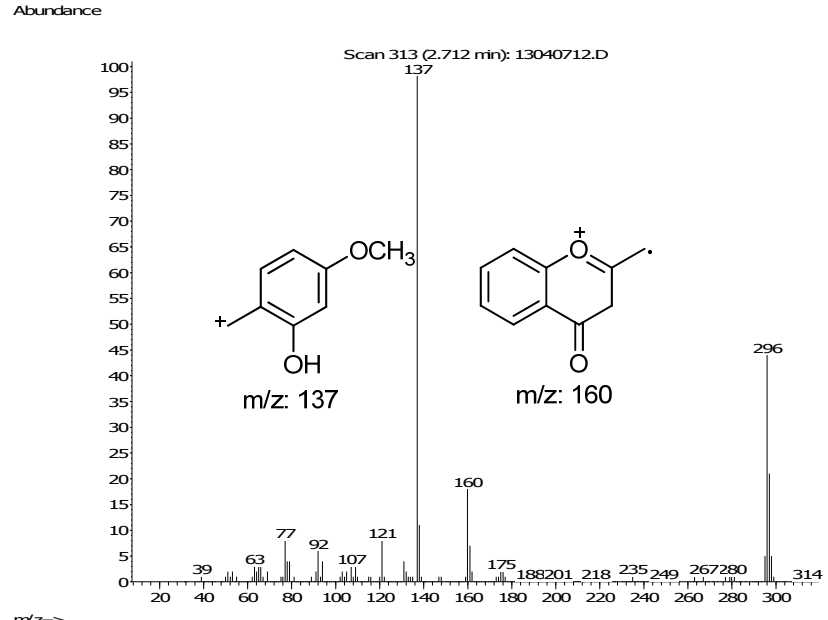

Compound 13

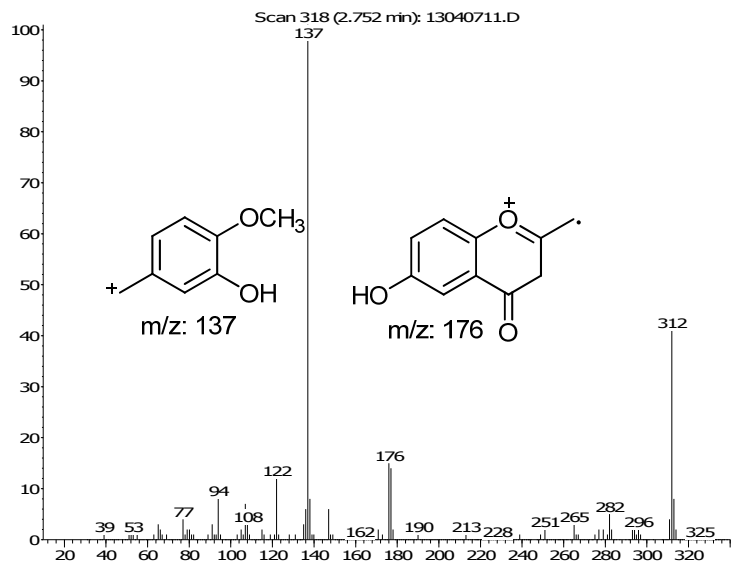

Compound 15

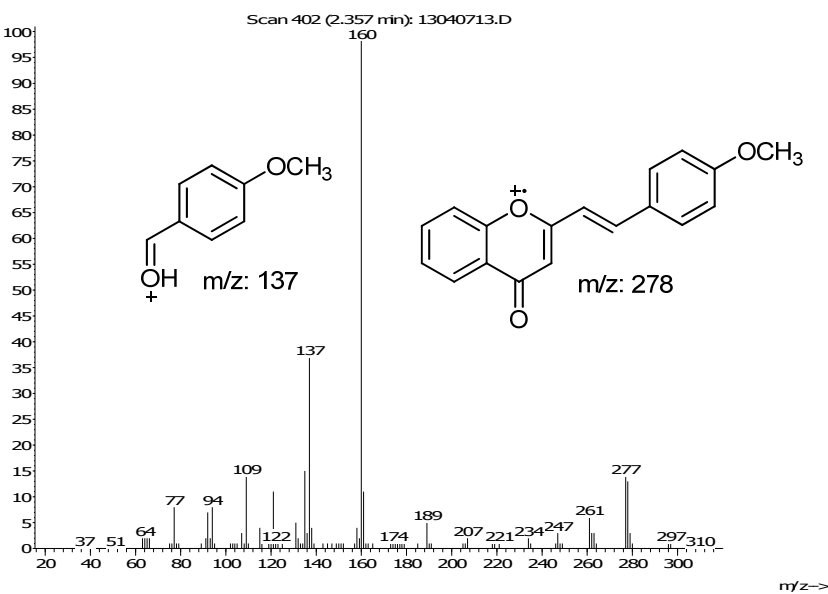

Compound 17

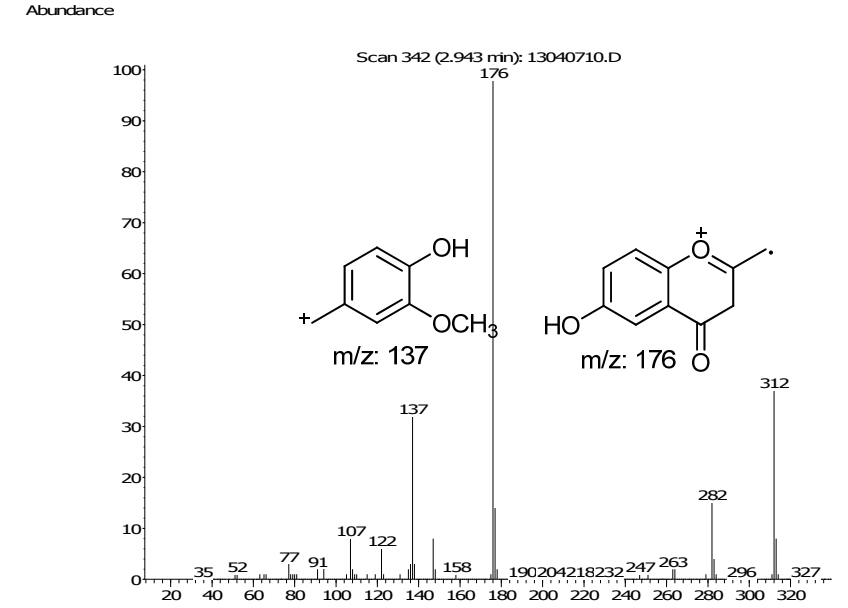

Compound 14

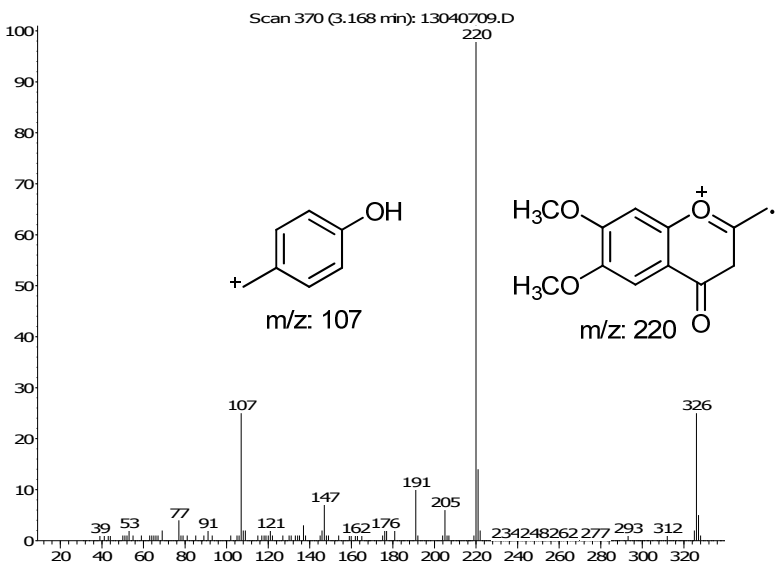

Compound 16

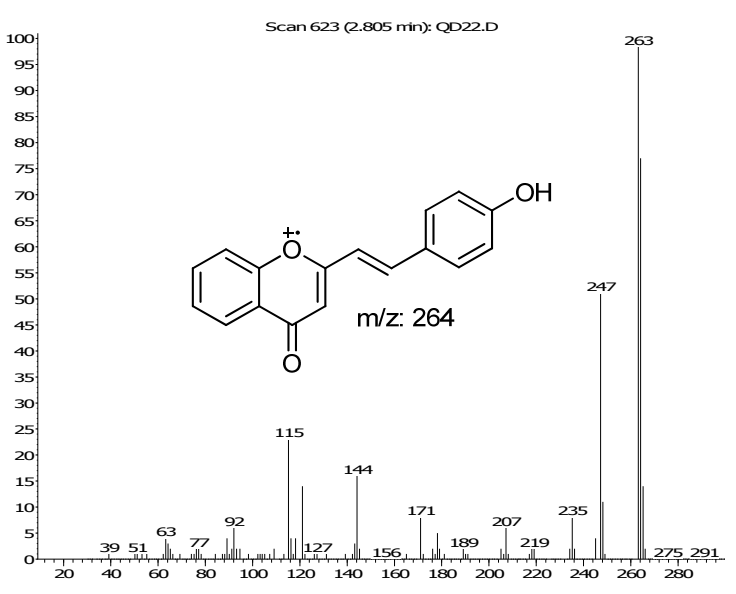

Compound 18 
Scheme 1. Proposed MS fragmentation patterns and characteristic fragments of 2-(2-phenylethyl)chromone.

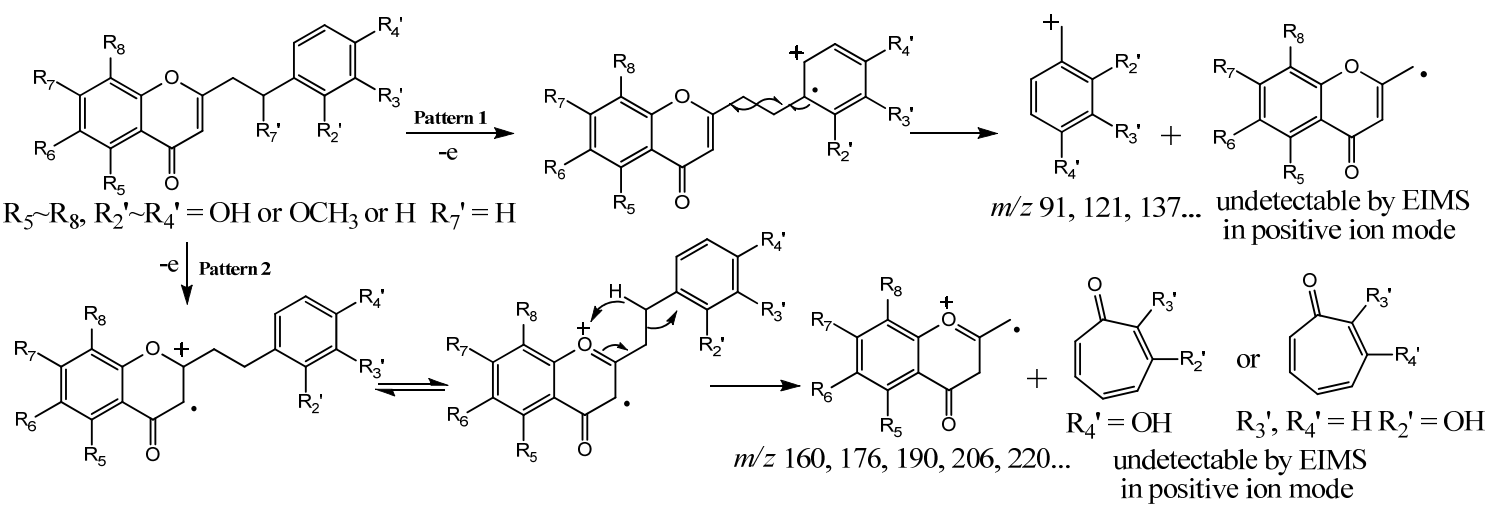

After further analyzing the MS data in Table 1, some rules have been discovered which should be helpful for characterization of 2-(2-phenylethyl)chromones by MS data. The 6, 4' positions are most likely to be substituted, closely followed by 7 and 3', meanwhile, only three compounds, Nos. 33 35, were substituted at the position of $7^{\prime}$ and all by hydroxyl groups. Thus, first we analyze the $7^{\prime}$ non-substituted compounds Nos. 1 32, whose relative fragment abundances are affected by their substitution patterns. We found that usually the substitution of a benzyl moiety has a greater impact than the substitution of chromone moiety, and the effect of methoxy substitution is similar to that of no substitution, while the opposite is true of hydroxy substitution; the $p$-substituted (4') groups have a greater impact than other positions on the relative abundance of fragments. Detailed analysis is as follows:

(1) (a) the benzyl moiety is non-substituted; (b) the benzyl moiety is substituted only by methoxy; (c) the benzyl moiety is substituted by both methoxy and hydroxy, as well as methoxy in the p-position (position $4^{\prime}$ ). All of the above mentioned situations favor the formation of benzyl fragment ions $(\mathrm{m} / \mathrm{z} 91,121,137)$, and in most cases these fragment ions are the base peaks;

(2) The benzyl moiety is substituted by hydroxy: (a) $p$ - or $o$-hydroxy substitution favors the formation of chromone fragment peaks $(m / z 160,176,190,220)$; (b) $m$-hydroxy can increase the relative abundances of benzyl fragment ions $(\mathrm{m} / \mathrm{z} 107,137)$.

Meanwhile, the chromone moiety substitution has a weaker impact to the relative abundances of fragment ions, but the effects are not so critical and the rule is not so clear.

Thus, the distribution of substituent groups $\left(-\mathrm{OH}\right.$ or $\left.-\mathrm{OCH}_{3}\right)$ at benzyl moiety and chromone moiety can be determined by the relative abundances of benzyl and chromone fragment peaks in MS spectra according to the above-mentioned rules.

The MS data in Table 1 will be taken for example to explain how to apply the rules. All the base peak of compounds Nos. 1 4, 8, 10, 11, 14, 19 are $\mathrm{m} / \mathrm{z} 91$, while the abundances of chromone fragment ions are very low or even negligible, corresponding to their non-substituted benzyl moiety as per rule 1(a). All the base peaks of compounds Nos. 9, 15, 20 23, 29 are $\mathrm{m} / \mathrm{z} \mathrm{121}$, while the abundances of chromone fragment ions are very low or even negligible, corresponding to their benzyl moiety substituted only by methoxy according to rule1(b). 
Table 1. MS characterization of 2-(2-phenylethyl)chromones in agarwood.

\begin{tabular}{|c|c|c|c|c|c|c|c|c|c|c|c|c|c|c|c|}
\hline \multirow[t]{2}{*}{ No. } & \multicolumn{4}{|c|}{ Chromone Moiety (CM) } & \multicolumn{4}{|c|}{ Benzyl Moiety (BM) } & \multirow[t]{2}{*}{$\mathbf{M}$} & \multirow[t]{2}{*}{ RA (\%) } & \multirow[t]{2}{*}{ BM } & \multirow[t]{2}{*}{ RA (\%) } & \multirow[t]{2}{*}{$\mathrm{CM}$} & \multirow[t]{2}{*}{ RA (\%) } & \multirow[t]{2}{*}{ R or NC } \\
\hline & $\mathbf{R}_{5}$ & $\mathbf{R}_{6}$ & $\mathbf{R}_{7}$ & $\mathbf{R}_{8}$ & $\mathbf{R}_{4^{\prime}}$ & $\mathbf{R}_{\mathbf{3}^{\prime}}$ & $\mathbf{R}_{2^{\prime}}$ & $\mathbf{R}_{7}$ & & & & & & & \\
\hline 1 & & & & & & & & & 250 & 20 & 91 & 100 & & & [18] \\
\hline 2 & & $\mathrm{OH}$ & & & & & & & 266 & 36 & 91 & 100 & & & $2,[10]$ \\
\hline 3 & & & $\mathrm{OH}$ & & & & & & 266 & 49 & 91 & 100 & & & {$[19]$} \\
\hline 4 & & & & $\mathrm{OH}$ & & & & & 266 & 58 & 91 & 100 & & & $6,[20]$ \\
\hline 5 & & & & & $\mathrm{OH}$ & & & & 266 & 40 & 107 & 28 & 160 & 100 & $7,[10]$ \\
\hline 6 & & & & & & $\mathrm{OH}$ & & & 266 & 100 & 107 & 58 & 160 & 10 & $\mathbf{8},[10]$ \\
\hline 7 & & & & & & & $\mathrm{OH}$ & & 266 & 46 & 107 & 18 & 160 & 100 & 9, $[10]$ \\
\hline 8 & & $\mathrm{OCH}_{3}$ & & & & & & & 280 & 48 & 91 & 100 & 161 & 10 & {$[18,21]$} \\
\hline 9 & & & & & $\mathrm{OCH}_{3}$ & & & & 280 & 27 & 121 & 100 & 160 & 3 & $\mathbf{1},[22]$ \\
\hline 10 & $\mathrm{OH}$ & & & $\mathrm{OH}$ & & & & & 282 & 100 & 91 & 100 & 191 & 2 & [23] \\
\hline 11 & & $\mathrm{OH}$ & & $\mathrm{OH}$ & & & & & 282 & 18 & 91 & 100 & 176 & 2 & [19] \\
\hline 12 & & $\mathrm{OH}$ & & & $\mathrm{OH}$ & & & & 282 & 58 & 107 & 60 & 176 & 100 & $\mathbf{1 0},[19]$ \\
\hline 13 & & $\mathrm{OH}$ & & & & & $\mathrm{OH}$ & & 282 & 60 & 107 & 13 & 176 & 100 & $\mathbf{1 1},[19]$ \\
\hline 14 & & $\mathrm{OH}$ & $\mathrm{OCH}_{3}$ & & & & & & 296 & 61 & 91 & 100 & 190 & 4 & [19] \\
\hline 15 & & $\mathrm{OH}$ & & & $\mathrm{OCH}_{3}$ & & & & 296 & 22 & 121 & 100 & & & $\mathbf{1 2},[18]$ \\
\hline 16 & & & & & $\mathrm{OH}$ & $\mathrm{OCH}_{3}$ & & & 296 & 37 & 137 & 52 & 160 & 100 & $\mathbf{3},[10]$ \\
\hline 17 & & & & & $\mathrm{OCH}_{3}$ & $\mathrm{OH}$ & & & 296 & 28 & 137 & 100 & 161 & 12 & $4,[10]$ \\
\hline 18 & & & & & $\mathrm{OCH}_{3}$ & & $\mathrm{OH}$ & & 296 & 48 & 137 & 100 & 160 & 27 & $\mathbf{1 3},[10]$ \\
\hline 19 & & $\mathrm{OCH}_{3}$ & $\mathrm{OCH}_{3}$ & & & & & & 310 & 84 & 91 & 100 & 219 & 10 & $\mathbf{5},[18,21]$ \\
\hline 20 & & $\mathrm{OCH}_{3}$ & & & & $\mathrm{OCH}_{3}$ & & & 310 & 60 & 121 & 100 & 190 & 8 & [18] \\
\hline 21 & & $\mathrm{OCH}_{3}$ & & & $\mathrm{OCH}_{3}$ & & & & 310 & 18 & 121 & 100 & 190 & 3 & [22] \\
\hline 22 & & $\mathrm{OH}$ & $\mathrm{OH}$ & & $\mathrm{OCH}_{3}$ & & & & 312 & 12 & 121 & 100 & 191 & 8 & [24] \\
\hline 23 & $\mathrm{OH}$ & & & $\mathrm{OH}$ & $\mathrm{OCH}_{3}$ & & & & 312 & 24 & 121 & 100 & & & [23] \\
\hline 24 & & $\mathrm{OH}$ & & & $\mathrm{OH}$ & $\mathrm{OCH}_{3}$ & & & 312 & 38 & 137 & 33 & 176 & 100 & $\mathbf{1 4},[10]$ \\
\hline 25 & & $\mathrm{OH}$ & & & $\mathrm{OCH}_{3}$ & $\mathrm{OH}$ & & & 312 & 42 & 137 & 100 & 176 & 16 & $15,[25]$ \\
\hline 26 & & $\mathrm{OCH}_{3}$ & $\mathrm{OCH}_{3}$ & & $\mathrm{OH}$ & & & & 326 & 41 & 107 & 23 & 220 & 100 & $16 *$ \\
\hline
\end{tabular}


Table 1. Cont.

\begin{tabular}{|c|c|c|c|c|c|c|c|c|c|c|c|c|c|c|c|}
\hline \multirow{2}{*}{ No. } & \multicolumn{3}{|c|}{ Chromone Moiety (CM) } & \multicolumn{5}{|c|}{ Benzyl Moiety (BM) } & \multirow{2}{*}{$\mathbf{M}$} & \multirow{2}{*}{ RA (\%) } & \multirow{2}{*}{ BM } & \multirow{2}{*}{ RA (\%) } & \multirow{2}{*}{$\mathbf{C M}$} & \multirow{2}{*}{ RA (\%) } & \multirow{2}{*}{$\mathrm{R}$ or NC } \\
\hline & $\mathbf{R}_{5}$ & $\mathbf{R}_{6}$ & $\mathbf{R}_{7}$ & $\mathbf{R}_{8}$ & $\mathbf{R}_{4^{\prime}}$ & $\mathbf{R}_{\mathbf{3}^{\prime}}$ & $\mathbf{R}_{2}$ & $\mathbf{R}_{7^{\prime}}$ & & & & & & & \\
\hline 27 & & $\mathrm{OCH}_{3}$ & & & $\mathrm{OH}$ & $\mathrm{OCH}_{3}$ & & & 326 & 17 & 137 & 30 & 190 & 100 & [19] \\
\hline 28 & & $\mathrm{OH}$ & & $\mathrm{OH}$ & $\mathrm{OH}$ & $\mathrm{OCH}_{3}$ & & & 328 & 20 & 137 & 34 & 190 & 100 & [26] \\
\hline 29 & & $\mathrm{OCH}_{3}$ & $\mathrm{OCH}_{3}$ & & $\mathrm{OCH}_{3}$ & & & & $340(310)$ & $18(16)$ & 121 & 100 & 220 & 2 & [23] \\
\hline 30 & & $\mathrm{OH}$ & $\mathrm{OCH}_{3}$ & & $\mathrm{OCH}_{3}$ & $\mathrm{OH}$ & & & 342 & 60 & 137 & 100 & 206 & 72 & [24] \\
\hline 31 & & $\mathrm{OCH}_{3}$ & $\mathrm{OCH}_{3}$ & & $\mathrm{OCH}_{3}$ & $\mathrm{OH}$ & & & 356 & 75 & 137 & 81 & 220 & 100 & [24] \\
\hline 32 & $\mathrm{OCH}_{3}$ & & & $\mathrm{OCH}_{3}$ & & $\mathrm{OCOCH}_{3}$ & & & 368 & 5 & 149 & 100 & & & [21] \\
\hline 33 & & & & & $\mathrm{OCH}_{3}$ & & & $\mathrm{OH}$ & $296(277)$ & $-(20)$ & 137 & 43 & 160 & 100 & $17 *$ \\
\hline 34 & & & & & $\mathrm{OH}$ & & & $\mathrm{OH}$ & $282(263)$ & $-(100)$ & & & & & $18 *$ \\
\hline 35 & & $\mathrm{OH}$ & & & & & & $\mathrm{OH}$ & $282(263)$ & $-(+)$ & 107 & 100 & 176 & + & [27] \\
\hline 36 & $\mathrm{OH}$ & $\mathrm{OCH}_{3}$ & & & & & & & 296 & + & 91 & 100 & 190 & + & [27] \\
\hline 37 & & $\mathrm{OH}$ & $\mathrm{OCH}_{3}$ & & $\mathrm{OH}$ & & & & 312 & + & 107 & + & 206 & 100 & [24] \\
\hline 38 & & $\mathrm{OCH}_{3}$ & $\mathrm{OH}$ & & $\mathrm{OCH}_{3}$ & & & & 326 & + & 121 & 100 & 206 & + & [28] \\
\hline 39 & & $\mathrm{OH}$ & & $\mathrm{OH}$ & $\mathrm{OCH}_{3}$ & $\mathrm{OH}$ & & & 328 & + & 137 & 100 & 192 & + & [24] \\
\hline 40 & & $\mathrm{OCH}_{3}$ & $\mathrm{OH}$ & & $\mathrm{OCH}_{3}$ & $\mathrm{OH}$ & & & 342 & + & 137 & 100 & 206 & + & [24] \\
\hline 41 & & $\mathrm{OCH}_{3}$ & $\mathrm{OCH}_{3}$ & & $\mathrm{OH}$ & $\mathrm{OCH}_{3}$ & & & 356 & + & 137 & + & 220 & 100 & [24] \\
\hline
\end{tabular}

RA: relative abundance; +: RA higher than 10\%; -: RA less than $10 \%$; : new compound; R: reference; NC: Number of compounds 1 18. 
All the benzyl moieties of compounds Nos. 17, 18, 24, 30, 31 are substituted by a methoxy and a hydroxy, and a methoxy in the $p$-position (position 4'), in accordance with rule 1(c). Their base peak is $m / z$ 137, except for compound No. 31, while the chromone fragment peaks showed different abundances for their different substituted chromone moieties. Taking compounds Nos. 30 and 31 as examples, both of them have the same $p$-methoxy- and $m$-hydroxy-substituted benzyl moiety, which favors the formation of a benzyl fragment ion at $m / z$ 137. The chromone moiety of compound No. 30 is substituted by $p$-hydroxy and $m$-methoxy, which results in a benzyl base peak at $m / z 137$ and a $72 \%$ chromone fragment peak at $\mathrm{m} / \mathrm{z}$ 206. However, the chromone moiety of compound No. 31 is substituted by both $m$ - and $p$-methoxy, which results in the chromone base peak at $m / z 220$ and an $81 \%$ benzyl fragment peak at $m / z 137$.

The benzyl moiety of compounds Nos. 5, 7, 12, 13, 16, 25 28 are substituted by $p$ - or $o$-hydroxy which are in favor of the formation of chromone fragment peaks $(\mathrm{m} / \mathrm{z} 160,176,190,220)$ in accordance with rule 2(a), while the benzyl fragment peaks showed different abundances for their different substituted chromone moieties. Taking compounds Nos. 5, 12, and 26 for example, all of the benzyl moieties are substituted by $p$-hydroxy groups, which favors the formation of chromone fragment peaks $(\mathrm{m} / \mathrm{z} 160,176,220)$ as base peaks. However, due to the different substitution on the chromone moiety, the abundance of the benzyl fragment peak at $m / z 107$ of compound No. 12 is over $60 \%$, while the abundance of the benzyl fragment peak at $\mathrm{m} / z 107$ of compounds No. 5 and No. 26 are $28 \%$ and $23 \%$, respectively.

The spectra were recorded with electron impact (EI) MS in positive ion mode, thus only cation ions, but no radical ions or neutral fragments can be detected. Based on the above results, we conjectured that the benzyl fragment cation ions and chromone fragment cation ions are most likely to be formed from two different cleavage methods. One is homolytic cleavage of the $\mathrm{CH}_{2}-\mathrm{CH}_{2}$ bond caused by radicals, which results in formation of benzyl fragment cation ions, such as $m / z 91,121,137,107$, etc. (Scheme 1). Another is rearrangement fragmentation, which results in formation of chromone fragment cation ions, such as $m / z 160,176,190,220$, etc. (Scheme 1). The occurrence of these two competitive cleavage mechanisms is mainly affected by the distribution of substituent groups ( $-\mathrm{OH}$ or $\left.-\mathrm{OCH}_{3}\right)$ on the benzyl and chromone moieties. Under the conditions of rules $1(\mathrm{a}) \sim 1(\mathrm{c})$ and $2(\mathrm{~b})$, the first cleavage method occurs primarily, which results in formation of benzyl fragment cation ions, while under the conditions of 2(a), the second cleavage method occurs primarily, which results in formation of chromone fragment cation ions.

The fragmentation patterns of 7'-hydroxy-substituted compounds, for example, compounds 17 and 18 (Nos. 33 and 34), are discussed as follows: the dehydration fragment ion at $m / z$ [M-18] was easily formed by chemical dehydration at the 7 ' position, therefore, the abundances of molecular ions are very low or even non-existent. If the ethyl bond is broken before dehydration, the characteristic benzyl fragment or chromone fragment ions can be formed, such as the case of compound 17, which shows the chromone base peak at $m / z 160$ and a $43 \%$ benzyl fragment ion at $m / z 137$. On the contrary, the whole molecule becomes a stable conjugated system after the vinyl is formed by dehydration, then it is difficult to break the vinyl bond, but various fragment peaks can be formed by dehydration or decarbonylation, such as in the case of compound 18 (Figure 1).

New 2-(2-phenylethyl)chromones have been reported, and some of these reports did not give any mass spectral data. The characteristic fragment peaks of these compounds (Nos. 35 41) were predicted 
on the base of the rules summarized above, and need to be verified experimentally in the future. Taking compound No. 41 for example, the substituent groups on the benzyl moiety, $p$-hydroxy and $m$-methoxy, are the same as in compound No. 27. Of them, the $p$-hydroxy favors the formation of a chromone fragment ion according to rule 2(a), while the $m$-methoxy favors the formation of a benzyl fragment ion according to rule 1(b). The chromone moiety of compound No. 41 is substituted by both $m$ - and $p$-methoxy groups, similar to the only $p$-methoxy-substituted chromone moiety of compound No. 27. Finally, we deduce that the aggregated effect of the substituents on compound No. 41 results in the chromone base peak at $m / z 220$, while the benzyl fragment peak at $\mathrm{m} / \mathrm{z} 137$ and molecular ion peak at $m / z 356$ also appear, similar to compound No. 27.

It is worthwhile to note that the mass spectral data for 5,6,7,8-tetrahydro-2-(2phenylethyl)chromones and diepoxytetrahydro-2-(2-phenylethyl)chromones identified in agarwood is not within the scope of the discussion in this paper.

Based on the abovementioned methods and rules, we analyzed an agarwood sample, which was harvested about nine months after injection of agarwood inducer into the trunk of a six-year-old A. sinensis tree at an A. sinensis plantation. At first, $0.5 \mathrm{mg}$ of the agarwood oil was analyzed by the GC/MS method. Figure 2 shows the total ion chromatogram, and the compounds characterized according to matches with compounds in the NIST05 and WILEY275 databases are listed in Table 2.

Figure 2. Total ion chromatogram of the agarwood oil.

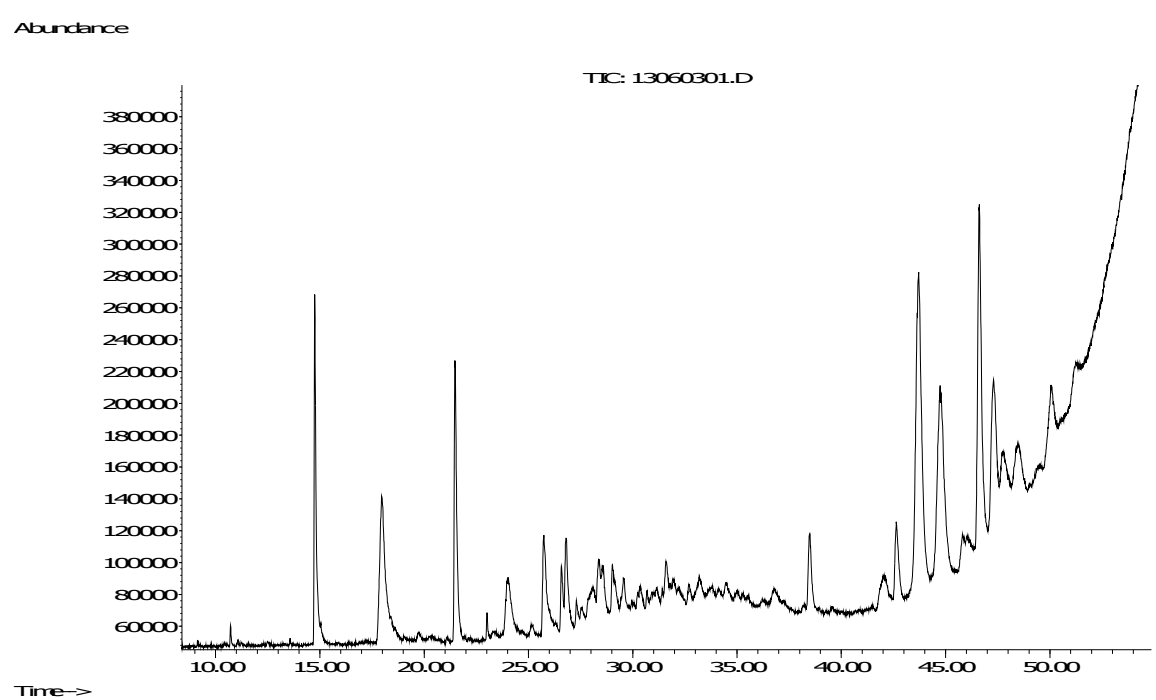

The results showed that only several simple volatile aromatic compounds, and an aliphatic acid, palmitic acid, together with 2-(2-phenylethyl)chromone have been identified, while in the retention times from $25.74 \mathrm{~min}$ to $38.59 \mathrm{~min}$, and from $38.59 \mathrm{~min}$ to $51.24 \mathrm{~min}$, there were a lot of compounds that were not identified. As we know, 2-(2-phenylethyl)chromone derivatives and characteristic sesquiterpenes are the main two compounds classes isolated from agarwood [1]. In addition, the molecular weights of sesquiterpenes are usually under 250, while the molecular weights of 2-(2-phenylethyl)chromones are at least 250. By comparing the retention times of the two kinds of compounds, we found that sesquiterpenes usually appear in front of 2-(2-phenylethyl)chromones. This rule can be found in the GC-MS analysis of agarwood of Japanese scholars and our group [14-16], so we deduced that the unidentified compounds with retention times from $25.74 \mathrm{~min}$ to $38.49 \mathrm{~min}$ are 
mainly sesquiterpenes, while the unidentified compounds with retention times from 38.49 min to 51.24 min are mainly 2-(2-phenylethyl)chromones, which was confirmed by their MS spectra.

Table 2. Chemical components and their relative content of agarwood oil.

\begin{tabular}{cccccc}
\hline No. & $\begin{array}{c}\text { Retention } \\
\text { time }\end{array}$ & Compound & $\begin{array}{c}\text { Molecular } \\
\text { formula }\end{array}$ & $\begin{array}{c}\text { Molecular } \\
\text { weight }\end{array}$ & $\begin{array}{c}\text { Relative } \\
\text { content (\%) }\end{array}$ \\
\hline YF1 & 10.72 & Nonanal & $\mathrm{C}_{9} \mathrm{H}_{18} \mathrm{O}$ & 142 & 0.19 \\
YF2 & 14.76 & Benzylacetone & $\mathrm{C}_{10} \mathrm{H}_{12} \mathrm{O}$ & 148 & 5.18 \\
YF3 & 17.96 & Benzenepropanoic acid & $\mathrm{C}_{9} \mathrm{H}_{10} \mathrm{O}_{2}$ & 150 & 6.81 \\
YF4 & 21.48 & Anisylacetone & $\mathrm{C}_{11} \mathrm{H}_{14} \mathrm{O}_{2}$ & 178 & 5.94 \\
YF5 & 24.02 & 3-(4-Methoxyphenyl)propionic acid & $\mathrm{C}_{11} \mathrm{H}_{16} \mathrm{O}_{2}$ & 180 & 2.59 \\
YF6 & 25.74 & Zingerone & $\mathrm{C}_{11} \mathrm{H}_{14} \mathrm{O}_{3}$ & 194 & 3.58 \\
YF7 & 26.80 & unidentified & & 206 & 2.57 \\
YF8 & 31.59 & Palmitic acid & $\mathrm{C}_{16} \mathrm{H}_{32} \mathrm{O}_{2}$ & 256 & 0.80 \\
YF9 & 38.49 & 2-(2-phenylethyl)chromone & $\mathrm{C}_{17} \mathrm{H}_{14} \mathrm{O}_{2}$ & 250 & 2.07 \\
YF10 & 42.03 & unidentified & & 266 & 2.91 \\
YF11 & 42.64 & unidentified & & 280 & 2.82 \\
YF12 & 43.71 & unidentified & & 282 & 13.99 \\
YF13 & 44.74 & unidentified & & 266 & 11.22 \\
YF14 & 45.81 & unidentified & & 296 & 1.44 \\
YF15 & 46.62 & unidentified & & 310 & 9.84 \\
YF16 & 47.30 & unidentified & & 312 & 5.37 \\
YF17 & 47.77 & unidentified & & 296 & 3.14 \\
YF18 & 48.46 & unidentified & 296 & 3.68 \\
YF19 & 50.05 & unidentified & 328 & 3.44 \\
YF20 & 51.24 & unidentified & 326 & 1.70 \\
\hline
\end{tabular}

In order to focus on the determination of 2-(2-phenylethyl)chromones, $70 \mathrm{mg}$ of the agarwood oil was dissolved in $0.5 \mathrm{~mL} \mathrm{MeOH}$, and then applied to a Sephadex LH-20 column $(1.2 \times 60 \mathrm{~cm})$ eluted with $120 \mathrm{~mL} \mathrm{MeOH}$ to give six fractions (Fr.1 6), which were analyzed by the GC/MS method and gave six total ion chromatograms (Figure 3). From these ion chromatograms, we found that 2-(2-phenylethyl)chromones were concentrated in Fr. 3 and Fr. 4, and especially Fr.4 possessed the best resolution ratio. Thus the compounds of Fr. 4 were further characterized by NIST05 and WILEY275 database matching, and then the MS spectra of unidentified compounds were drawn and characterized by the methods and rules mentioned above, and referring to the MS data in Table 1. Finally fifteen compounds were characterized as 2-(2-phenylethyl)chromones, one of them from Fr. 3 (Fr. 3-23). The results are shown in Table 3, and Figure 4. The detailed identification procedures are as follows: first, the number of hydroxy and methoxy groups can be deduced on the basis of the molecular ion peak or molecular weight (MW) through the formula $(30 \mathrm{~m}+16 \mathrm{n}=\mathrm{MW}-250)$ in Table 3. Then we found that all the base peak of compounds Fr. 4-10 Fr. 4-26 are benzyl fragment peaks $(\mathrm{m} / \mathrm{z}$ 91, 121, 137), which are generated by the first cleavage method and in accordance with the conditions of rules $1(\mathrm{a}) \sim 1(\mathrm{c})$, and 2 (b). 
Figure 3. Total ion chromatogram for Fr.1 6 of agarwood oil.
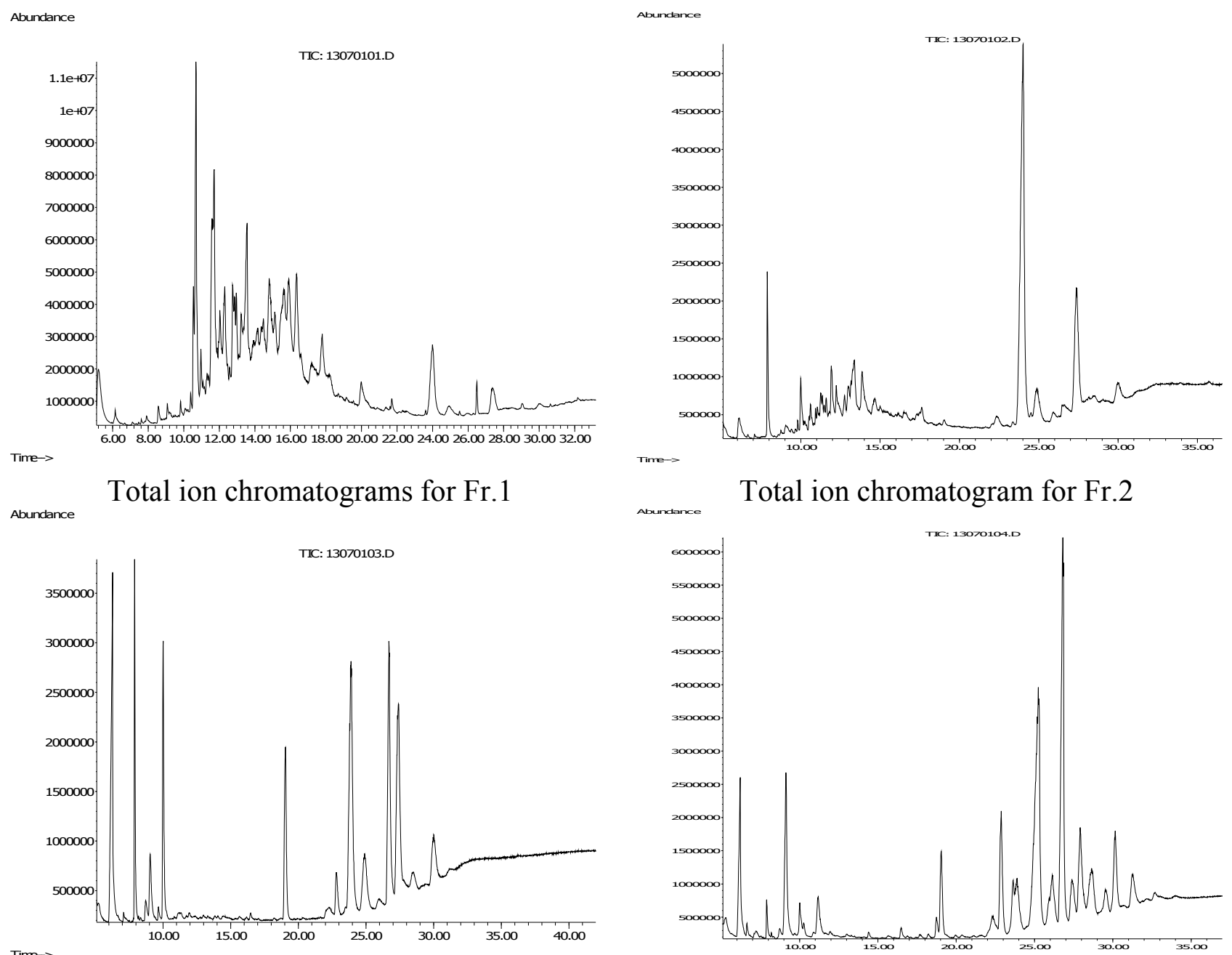
Time->

Total ion chromatogram for Fr.3

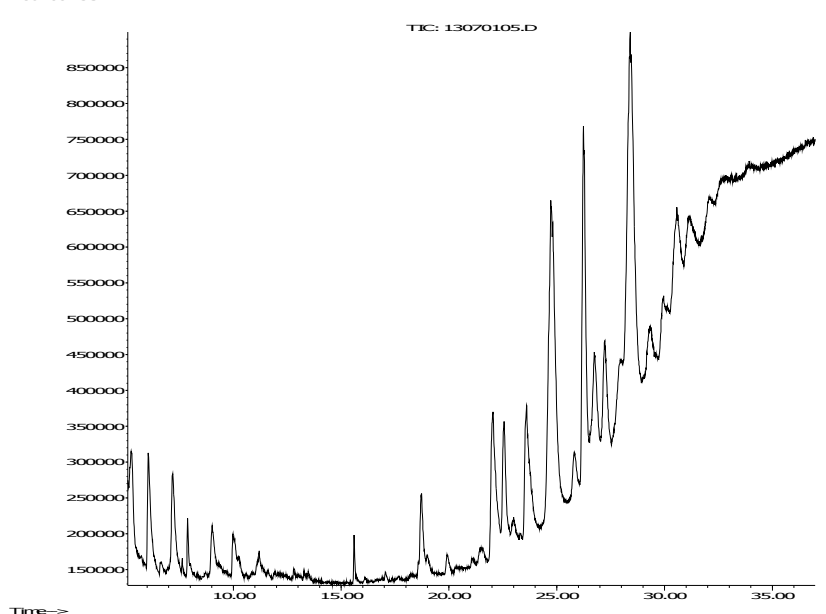

Total ion chromatogram for Fr.5

Total ion chromatogram for Fr.4 Abundance

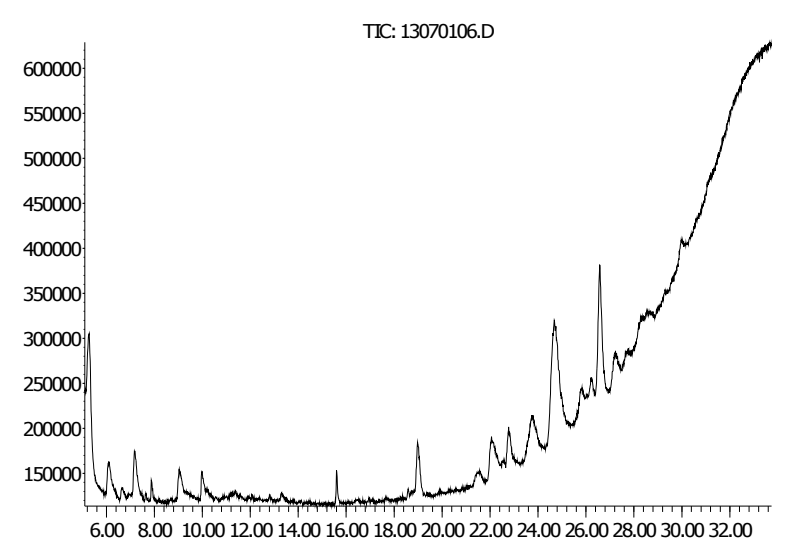

Total ion chromatogram for Fr.6 
Table 3. 2-(2-Phenylethyl)chromone preliminarily identified by their MS characterization and chemical components identified by database matching of Fraction 4 of agarwood oil.

\begin{tabular}{|c|c|c|c|c|c|c|c|c|}
\hline No. & $\begin{array}{c}\text { Retention } \\
\text { time }\end{array}$ & $\begin{array}{l}\text { Compounds identified by } \\
\text { database matching }\end{array}$ & \multicolumn{4}{|c|}{ Molecular formula } & \multicolumn{2}{|c|}{ Molecular weight } \\
\hline Fr.4-1 & 6.21 & Benzenepropanoic acid & \multicolumn{4}{|c|}{$\mathrm{C}_{9} \mathrm{H}_{10} \mathrm{O}_{2}$} & \multicolumn{2}{|c|}{150} \\
\hline Fr.4-2 & 6.64 & Melitol & \multicolumn{4}{|c|}{$\mathrm{C}_{9} \mathrm{H}_{8} \mathrm{O}_{2}$} & \multicolumn{2}{|c|}{148} \\
\hline Fr.4-3 & 7.22 & 3,4-dimethoxy-Phenol & \multicolumn{4}{|c|}{$\mathrm{C}_{8} \mathrm{H}_{10} \mathrm{O}_{3}$} & \multicolumn{2}{|c|}{154} \\
\hline Fr.4-4 & 7.90 & Anisylacetone & \multicolumn{4}{|c|}{$\mathrm{C}_{11} \mathrm{H}_{14} \mathrm{O}_{2}$} & \multicolumn{2}{|c|}{178} \\
\hline Fr.4-5 & 8.72 & Raspberry ketone & \multicolumn{4}{|c|}{$\mathrm{C}_{10} \mathrm{H}_{12} \mathrm{O}_{2}$} & \multicolumn{2}{|c|}{164} \\
\hline Fr.4-6 & 9.13 & $\begin{array}{l}\text { 3-(4-Methoxyphenyl)propionic } \\
\text { acid }\end{array}$ & \multicolumn{4}{|c|}{$\mathrm{C}_{11} \mathrm{H}_{16} \mathrm{O}_{2}$} & \multicolumn{2}{|c|}{180} \\
\hline Fr.4-7 & 10.01 & Zingerone & \multicolumn{4}{|c|}{$\mathrm{C}_{11} \mathrm{H}_{14} \mathrm{O}_{3}$} & \multicolumn{2}{|c|}{194} \\
\hline Fr.4-8 & 11.19 & Methylm-methoxymandelate & \multicolumn{4}{|c|}{$\mathrm{C}_{10} \mathrm{H}_{12} \mathrm{O}_{4}$} & \multicolumn{2}{|c|}{196} \\
\hline Fr.4-9 & 16.47 & 1,5-diphenyl-1-Penten-3-one & \multicolumn{4}{|c|}{$\mathrm{C}_{17} \mathrm{H}_{16} \mathrm{O}$} & 236 & \\
\hline \multirow{3}{*}{ No. } & \multirow{3}{*}{$\begin{array}{l}\text { Retention } \\
\text { time }\end{array}$} & \multirow{3}{*}{$\begin{array}{l}\text { 2-(2-Phenylethyl)chromones } \\
\text { preliminarily identified by their } \\
\text { MS characterization }\end{array}$} & \multicolumn{4}{|c|}{ Substituent condition } & \multicolumn{2}{|c|}{$\begin{array}{c}\text { MS } \\
\text { characterization }\end{array}$} \\
\hline & & & \multicolumn{2}{|c|}{$\begin{array}{c}\text { Chromone } \\
\text { moiety }\end{array}$} & \multicolumn{2}{|c|}{ Benzyl moiety } & \multirow{2}{*}{$\begin{array}{l}\text { Molecular } \\
\text { ion peak }\end{array}$} & \multirow{2}{*}{$\begin{array}{l}\text { Base } \\
\text { peak }\end{array}$} \\
\hline & & & OH & $\mathrm{OCH}_{3}$ & OH & $\mathrm{OCH}_{3}$ & & \\
\hline Fr.4-10 & 19.04 & 2-(2-phenylethyl)chromone & 0 & 0 & 0 & 0 & 250 & 91 \\
\hline Fr.4-11 & 22.33 & No. 2 or No. 3 or No. 4 & 1 & 0 & 0 & 0 & 266 & 91 \\
\hline Fr.4-12 & 22.88 & No. 8 & 0 & 1 & 0 & 0 & 280 & 91 \\
\hline Fr.4-13 & 23.63 & Similar compound as No. 14 & 1 & 1 & 0 & 0 & 296 & 91 \\
\hline Fr.4-14 & 23.90 & No. 10 or No. 11 & 2 & 0 & 0 & 0 & 282 & 91 \\
\hline Fr.4-15 & 25.24 & No. 2 or No. 3 or No. 4 & 1 & 0 & 0 & 0 & 266 & 91 \\
\hline Fr.4-16 & 25.97 & Similar compound as No. 14 & 1 & 1 & 0 & 0 & 296 & 91 \\
\hline Fr.4-17 & 26.14 & Two compounds mixture & & & & & 296,310 & 91,121 \\
\hline Fr.4-18 & 26.81 & No. 19 & 0 & 2 & 0 & 0 & 310 & 91 \\
\hline Fr.4-19 & 27.39 & No. 22 or No. 23 & 2 & 0 & 0 & 1 & 312 & 121 \\
\hline Fr.4-20 & 27.92 & Similar compound as No. 14 & 1 & 1 & 0 & 0 & 296 & 91 \\
\hline Fr.4-21 & 28.67 & No.15 & 1 & 0 & 0 & 1 & 296 & 121 \\
\hline Fr.4-22 & 29.52 & Similar compound as No. 38 & 1 & 1 & 0 & 1 & 326 & 121 \\
\hline Fr.3-23 & 30.02 & Similar compound as No. 39 & 2 & 0 & 1 & 1 & 328 & 137 \\
\hline Fr.4-24 & 30.12 & New compound & 3 & 0 & 0 & 1 & 328 & 121 \\
\hline Fr.4-25 & 30.15 & No.29 & 0 & 2 & 0 & 1 & 340 & 121 \\
\hline Fr.4-26 & 31.25 & Similar compound as No. 38 & 1 & 1 & 0 & 1 & 326 & 121 \\
\hline
\end{tabular}

All the base peaks of Fr.4-10 Fr.4-16, Fr.4-18 and Fr.4-20 are $m / z$ 91, which indicates these molecules have a non-substituted benzyl moiety and the substituent groups are located on the chromone moiety. The molecular ion peak of Fr.4-11 and Fr.4-15 is $m / z 266$, which indicates there is only one hydroxy substituent group in each of them. Since the benzyl moiety is non-substituted, the hydroxy is substituted on the chromone moiety. The position of substitution is difficult to determine, so their structures should be one of No. 2 No. 4, respectively. Similarly, the molecular ion peak of Fr.4-14 is at $m / z$ 282, which indicates the chromone moiety is substituted by two hydroxyl groups, so its structure may be No. 10 or No. 11. The mass spectra of Fr.4-13, Fr.4-16, Fr.4-20 are quite similar, 
with the same molecular ion peak at $m / z 296$, which indicates the chromone moieties are substituted by one hydroxy and one methoxy, similar to No. 14. Finally, only compound No. 8 possess similar MS data as that of Fr.4-12, therefore Fr.4-12 is identified as No. 8. Similarly, Fr.4-18 is identified as No. 19.

All the base peaks of Fr.4-19, Fr.4-21, Fr.4-22, Fr.4-24, Fr.4-25 and Fr.4-26 are $\mathrm{m} / z$ 121, which indicates these molecules have a methoxy-substituted benzyl moiety, and the position of the methoxy group is most likely at the $p$-position (position 4'), while the other substituent groups are located on the chromone moiety. The molecular ion peak of Fr.4-19 is at $\mathrm{m} / \mathrm{z} 312$, indicating the chromone moiety is substituted by two hydroxy groups, so its structure is likely to be No. 22 or No. 23. The mass spectra of Fr.4-22 and Fr.4-26 are very similar, with the same molecular ion peak at $m / z$ 326, which indicates that their chromone moieties are substituted by one hydroxy and one methoxy, similar to No. 38. Only compound No. 15 possesses similar MS data to that of Fr.4-21, therefore Fr.4-21 is identified as No.15. Similarly, Fr.4-25 is identified as No. 29. The molecular ion peak of Fr.4-24 is at $\mathrm{m} / \mathrm{z} 328$, which indicates the chromone moiety is substituted by three hydroxy groups. Such a compound has not been reported, so Fr.4-24 should be a new compound.

Figure 4. MS spectra and structures characterization of 2-(2-phenylethyl)chromones of fraction 4 of agarwood oil.

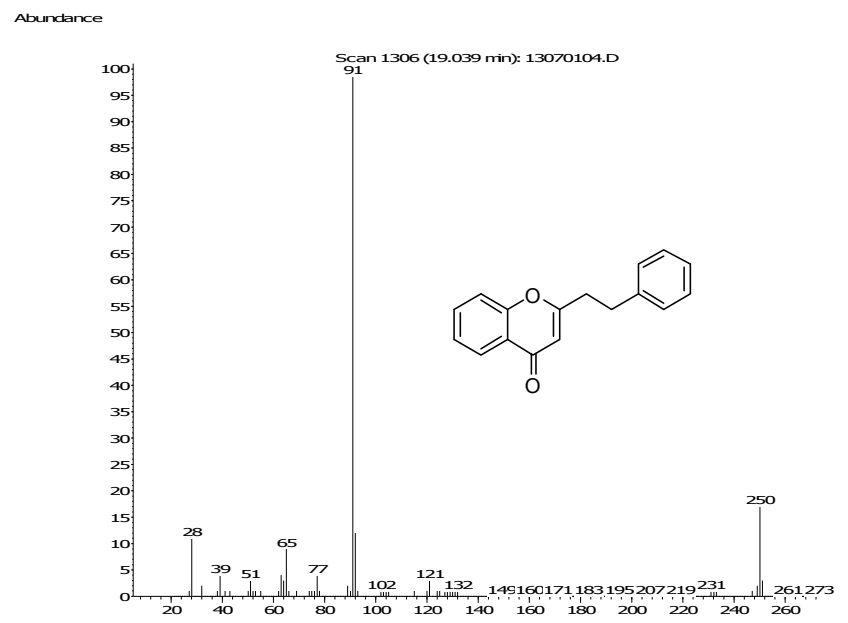

Fr.4-10

Aburdance

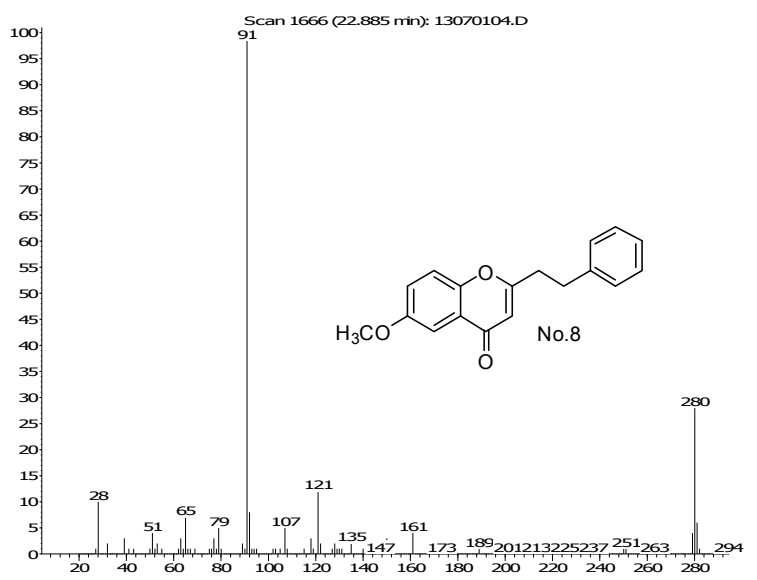

Fr.4-12

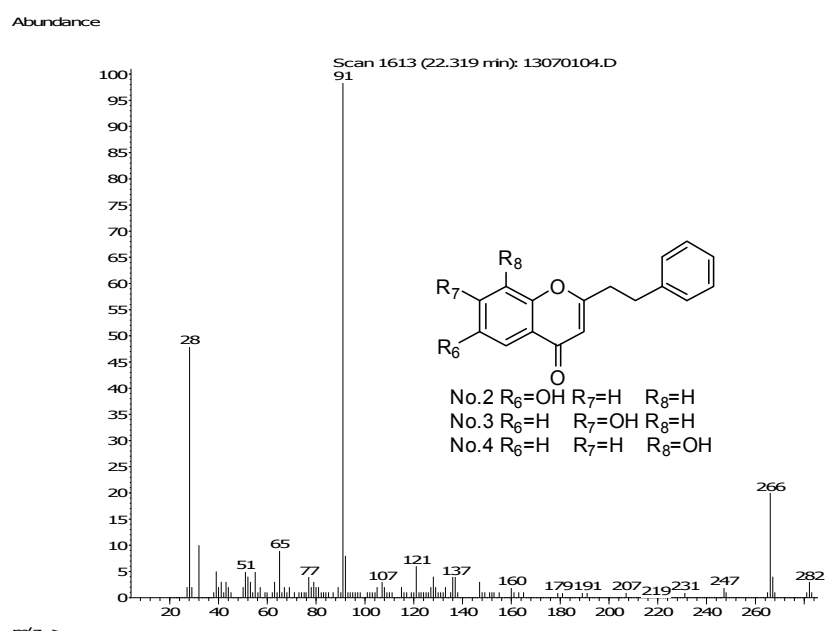

Fr.4-11
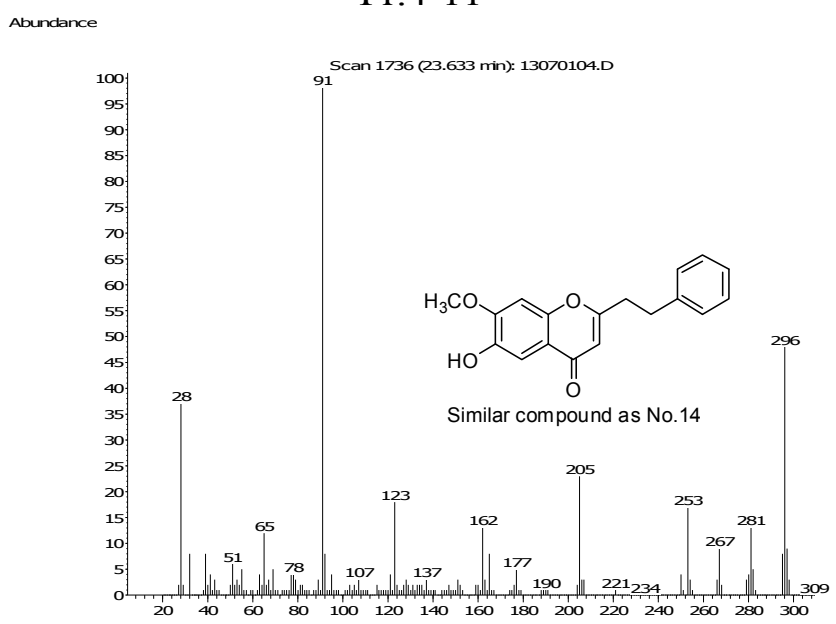

Fr.4-13 
Figure 4. Cont.

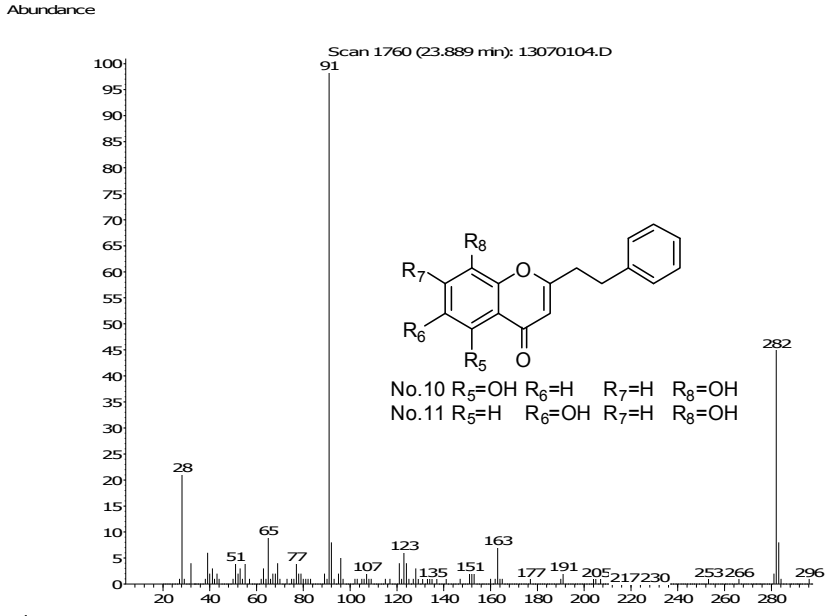

Fr.4-14

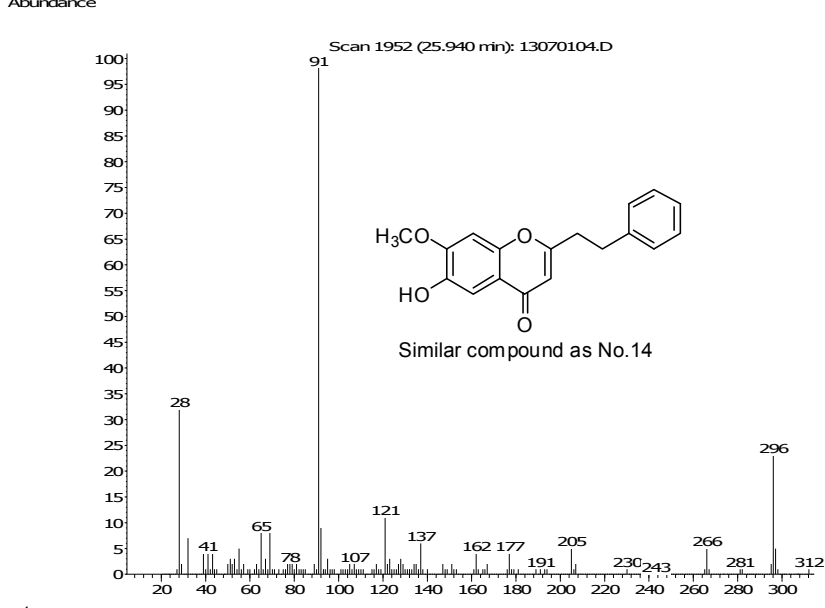

Fr.4-16

Abundance

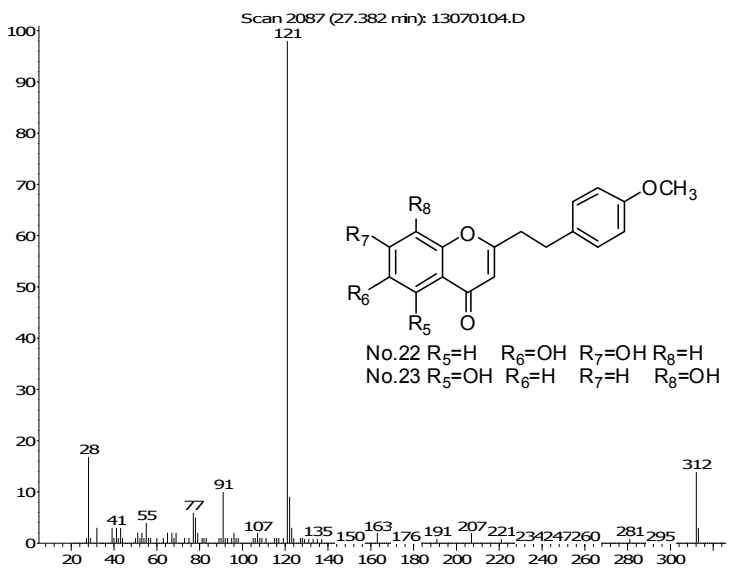

Fr.4-19

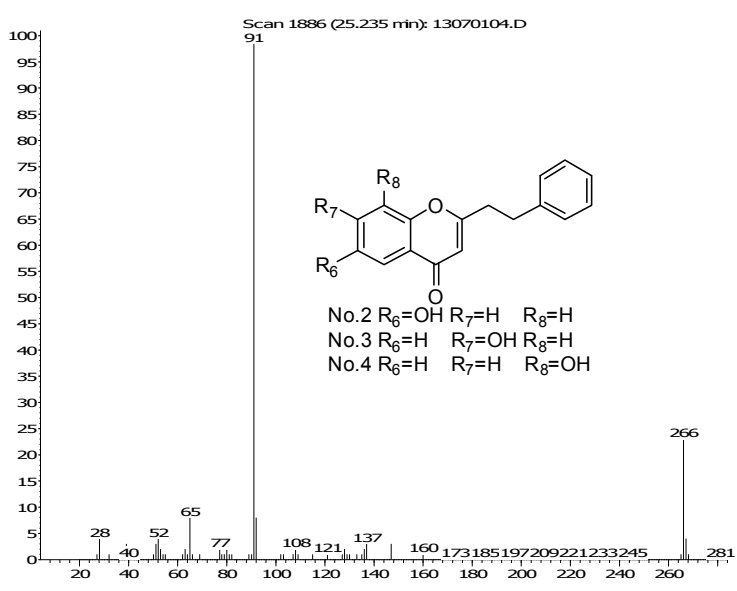

Fr.4-15

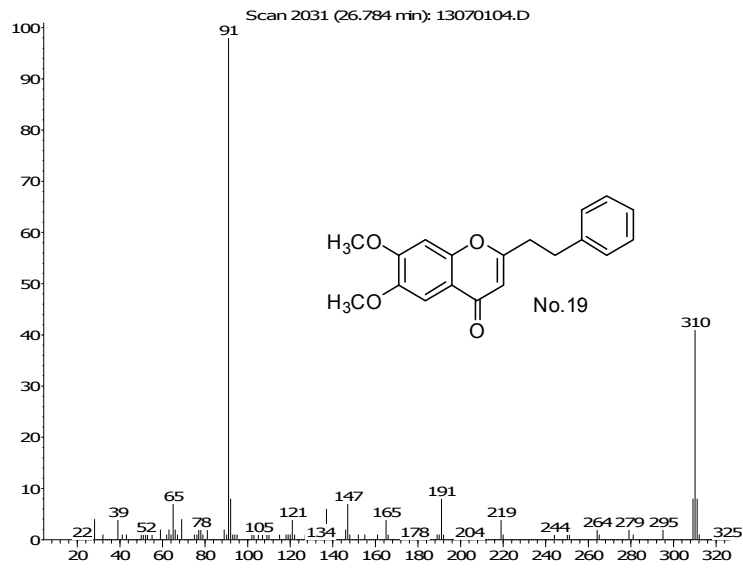

Fr.4-18

Abundance

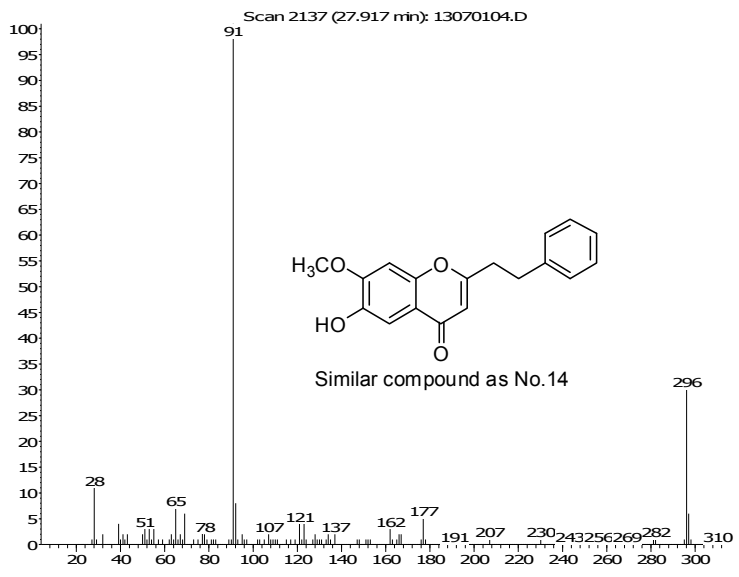

Fr.4-20 
Figure 4. Cont.

Abundance

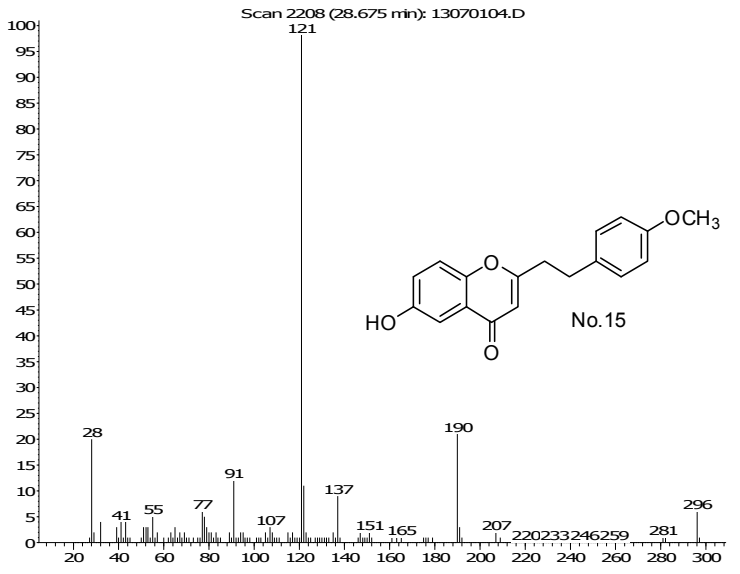

Fr.4-21

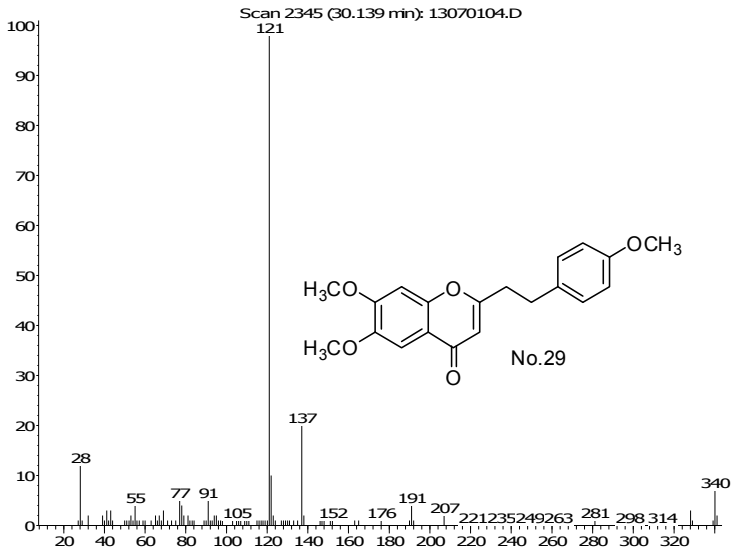

Fr.4-25

Abundance

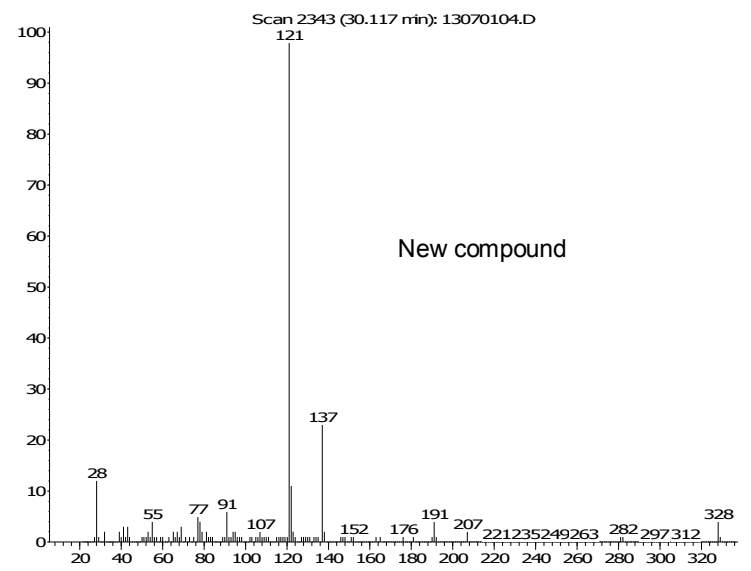

Fr.4-24

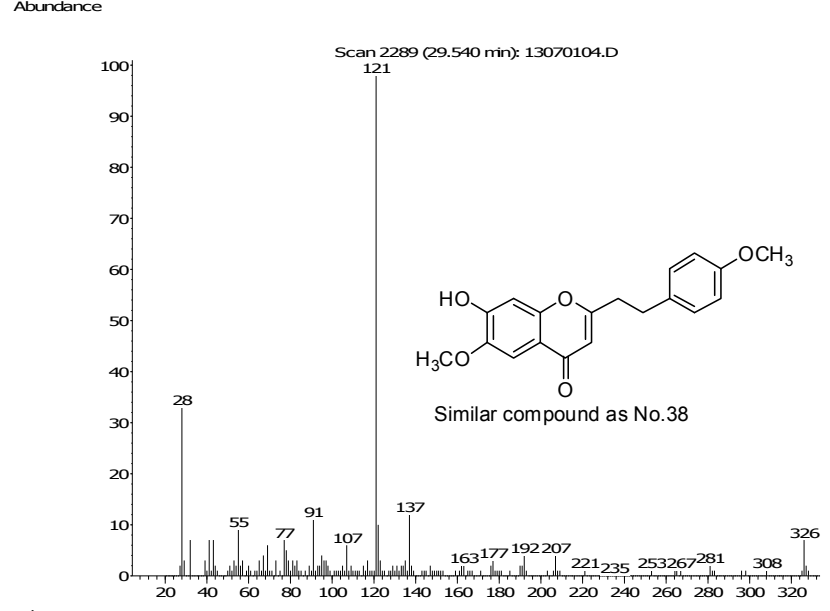

Fr.4-22

Abundance

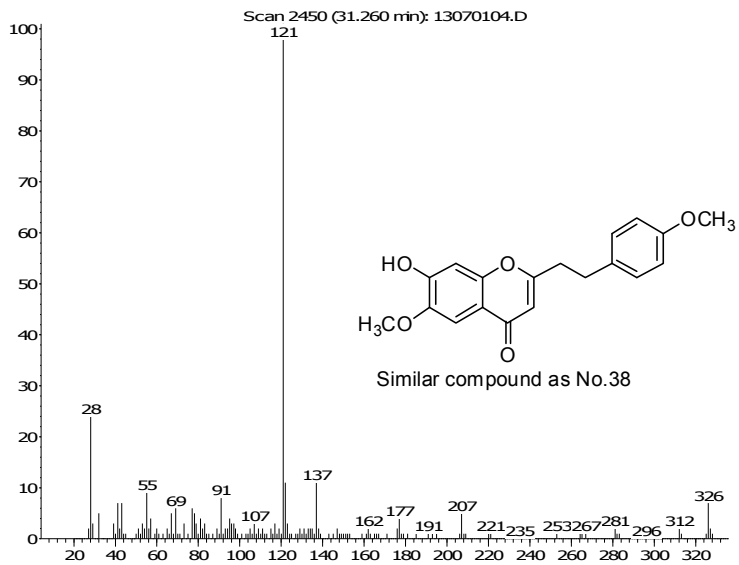

Fr.4-26

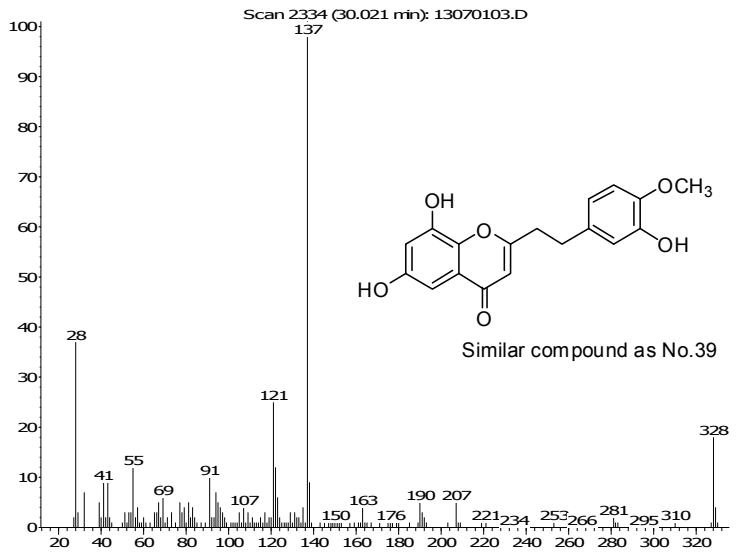

Fr.3-23 
Figure 4. Cont.

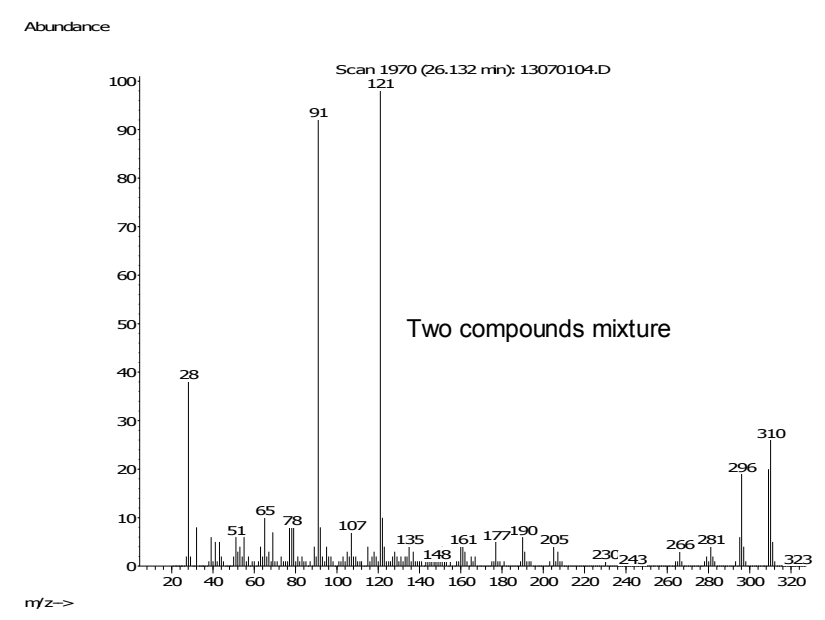

Fr.4-17

The base peak of Fr.3-23 is $m / z$ 137, which indicates the molecule has a $p$-methoxy- and a hydroxyl-substituted benzyl moiety. The molecular ion peak is at $m / z 328$, which indicates the chromone moiety is substituted by two hydroxy groups, so its structure is likely to be No. 39 .

There are two molecular ions at $\mathrm{m} / \mathrm{z} 296$ and $\mathrm{m} / \mathrm{z}$ 310, and two fragment peaks at $\mathrm{m} / \mathrm{z} 121(100 \%)$ and $m / z 91(94 \%)$ in the mass spectrum of Fr.4-17, indicating a mixture of two compounds.

2-(2-Phenylethyl)chromone derivatives, mainly found in agarwoods from the Aquilaria species [18,19,21-31], and rarely found in other species [20,32-34], are irreplaceable components for the special fragrance of agarwood, but they have seldom been characterized by GC-MS [14-17], which was often used to analyze the constituents of volatile oil of agarwood and many sesquiterpenes, such as agarospirol, baimuxinal, baimuxinol, together with some simple volatile aromatic compounds, such as benzylacetone, anisylacetone, have been characterized [35-37]. One reason maybe there are not too many MS spectra of 2-(2-phenylethyl)chromones in the database for matching, and people know little about the MS characterization of 2-(2-phenylethyl)chromones. The melting points of most of 2-(2-phenylethyl)chromones are under $200^{\circ} \mathrm{C}$, which are suitable for GC-MS analysis. Future work will focus on obtaining more 2-(2-phenylethyl)chromones standards to enrich the MS spectra database, so that a more comprehensive characterization of these compounds by GC-MS analysis is possible.

\section{Experimental}

\subsection{GC-MS Analysis}

A Hewlett Packard GC 6890 gas chromatography instrument coupled with a Mass Selective Detector (5975C, Agilent Technologies, Santa clara, CA, USA) was used for the analysis. Separation of the samples by gas chromatography was carried out using a Zebron ZB-5MSi 5\% Phenyl 95\% Dimethylpolysiloxane capillary column $(30 \mathrm{~m} \times 0.25 \mathrm{~mm} \times 0.25 \mu \mathrm{m})$ (Phenomenex, Torrance, CA, USA). Samples $(0.5 \mathrm{mg})$ were dissolved in dichloromethane, then $1.0 \mu \mathrm{L}$ of solvent was injected into the front inlet of the gas chromatograph operating at $250{ }^{\circ} \mathrm{C}$ with $40: 1$ of split ratio. The flow rate of the helium (carrier gas) was $1.0 \mathrm{~mL} / \mathrm{min}$. For the agarwood oil, the oven program commenced at $50{ }^{\circ} \mathrm{C}$ and increased to $250{ }^{\circ} \mathrm{C}$ at a rate of $5{ }^{\circ} \mathrm{C} / \mathrm{min}$, and finally increased to $310^{\circ} \mathrm{C}$ at a rate of $10{ }^{\circ} \mathrm{C} / \mathrm{min}$, 
then held for $10 \mathrm{~min}$. For Fr.1 6, the oven program commenced at $100{ }^{\circ} \mathrm{C}$ and increased to $200{ }^{\circ} \mathrm{C}$ at a rate of $10^{\circ} \mathrm{C} / \mathrm{min}$, and finally increased to $310^{\circ} \mathrm{C}$ at a rate of $5{ }^{\circ} \mathrm{C} / \mathrm{min}$, then held for $10 \mathrm{~min}$. The interface temperature was $280{ }^{\circ} \mathrm{C}$. Ionization of the compounds by electron impact (EI) was obtained using an emission current of $70 \mathrm{eV}$. The ion source temperature was set at $230{ }^{\circ} \mathrm{C}$ and scan scope was from 20 to $450 \mathrm{amu}$. Figures 2 and 3 show the total ion chromatograms of the agarwood oil and Fr.1 6. The relative contents of the compounds were determined by normalization. The compounds were characterized by NIST05 and WILEY275 database matching.

\subsection{Plant Material}

The agarwood inducer, which remains a technical secret, was injected into the trunk of six-year-old A. sinensis trees on an A. sinensis plantation located at Yanfeng Town at Haikou City, Hainan Province, China, at September, 2012. The agarwood was then harvested at May, 2013, about nine months after agarwood-inducing operation. The dark resins of the agarwood were exposed after getting rid of white wood (Figure 5). On the surface of this agarwood, the lines of dark resins could be clearly seen by using magnifying glass, and the pleasant fragrance could be smelled after burning. The specimen (YF 20130502) is deposited at Institute of Tropical Bioscience and Biotechnology, Chinese Academy of Tropical Agricultural Sciences.

Figure 5. The photo of the artificial agarwood sample. (a) The whole piece of the agarwood. (b) The partially magnified agarwood.

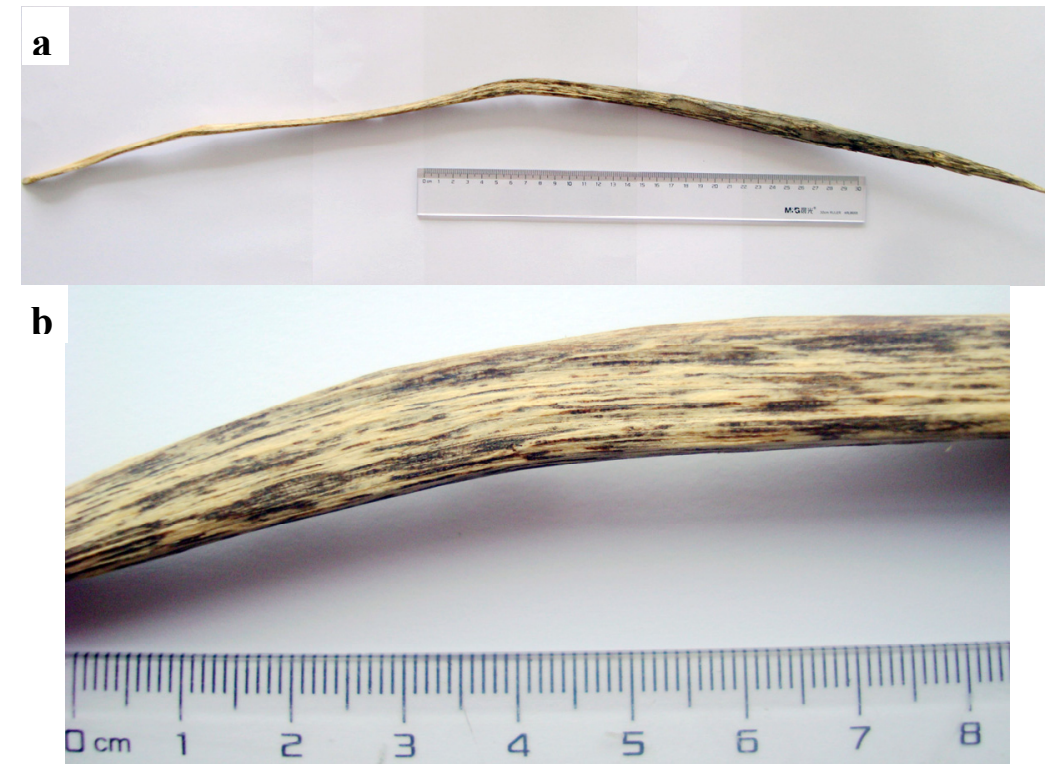

\subsection{Extraction and Separation}

The crushed agarwood (1.32 g, dry weight) was soaked in $\mathrm{Et}_{2} \mathrm{O}(3 \times 10 \mathrm{~mL})$ and extracted by the ultrasound method. The $\mathrm{Et}_{2} \mathrm{O}$ extract $(30 \mathrm{~mL})$ was filtered and evaporated to get brownish yellow oil (74.4 mg, $5.6 \%$ yield). A sample of this oil $(0.5 \mathrm{mg})$ was analyzed by GC-MS. Another sample of oil $(70 \mathrm{mg})$ was dissolved in $0.5 \mathrm{~mL} \mathrm{MeOH}$, and then applied to a Sephadex LH-20 column $(1.2 \times 60 \mathrm{~cm})$ eluted with $120 \mathrm{~mL} \mathrm{MeOH}$ to separate it into six fractions (Fr.1 6). 


\section{Conclusions}

MS characterization of all the 2-(2-phenylethyl)chromones in agarwood was summarized in Table 1 and a formula $(30 \mathrm{~m}+16 \mathrm{n}=\mathrm{MW}-250)$ was provided to calculate the number of methoxy $(\mathrm{m})$ or hydroxy (n) groups according to the molecular ion peak or molecular weight (MW) of 2-(2-phenylethyl)chromones only substituted by methoxy or/and hydroxy groups. We deduced that the characteristic fragmentation behavior of the 2-(2-phenylethyl)chromones is the cleavage of the $\mathrm{CH}_{2}-\mathrm{CH}_{2}$ bond between chromone moiety and phenyl moiety. Thus, characteristic fragment ions, such as $m / z 91\left[\mathrm{C}_{7} \mathrm{H}_{7}\right], 107\left[\mathrm{C}_{7} \mathrm{H}_{6}+\mathrm{OH}\right], 121\left[\mathrm{C}_{7} \mathrm{H}_{6}+\mathrm{OCH}_{3}\right], 137\left[\mathrm{C}_{7} \mathrm{H}_{5}+\mathrm{OH}+\mathrm{OCH}_{3}\right]$ are formed by differently substituted benzyl moieties, while characteristic fragment ions, such as $m / z 160\left[\mathrm{C}_{10} \mathrm{H}_{8} \mathrm{O}_{2}\right]$, $176\left[\mathrm{C}_{10} \mathrm{H}_{7} \mathrm{O}_{2}+\mathrm{OH}\right], 190\left[\mathrm{C}_{10} \mathrm{H}_{7} \mathrm{O}_{2}+\mathrm{OCH}_{3}\right], 220\left[\mathrm{C}_{10} \mathrm{H}_{6} \mathrm{O}_{2}+\mathrm{OCH}_{3} \times 2\right]$ are formed by differently substituted chromone moieties. Furthermore, rules regarding to the relationships between the positions of the hydroxy or methoxy groups and the relative abundances of benzyl and chromone fragment ions have been determined. Elucidation of how the positions of hydroxy or methoxy groups affect the relative abundances of benzyl and chromone fragment peaks are also provided. In conclusion, 2-(2-phenylethyl)chromones can be preliminarily determined by their MS spectra. The above mentioned methods and the MS data in Table 1 were applied to the analysis in an agarwood sample. Fifteen unidentified compounds analyzed by GC-MS and NIST05 and WILEY275 database matching were preliminarily determined as 2-(2-phenylethyl)chromones by analysis of their MS spectra and by comparison of their spectra with those in Table 1, which give a good example and proved the methods are feasible. The methods presented in this paper should be helpful for the analysis and characterization of 2-(2-phenylethyl)chromones in agarwood by GC-MS, and provides a scientifically sound, fast and reliable evaluation method for the quality of agarwood.

\section{Acknowledgments}

This work was financially supported by Special Fund for Agro-scientific Research in the Public Interest (201303117), National Support Science and Technology Subject (2013BAI11B04), Major Technology Project of Hainan Province (ZDZX2013013, ZDZX2013023-1), and Fundamental Research Funds for Central Public Welfare Research Institutes (Chinese Academy of Tropical Agricultural Sciences, No. 1630052012014).

\section{Conflicts of Interest}

The authors declare no conflict of interest.

\section{References}

1. Naef, R. The volatile and semi-volatile constituents of agarwood, the infected heartwood of Aquilaria species: A review. Flavour Fragr. J. 2011, 26, 73-87.

2. Lancaster, C.; Espinoza, E. Evaluating agarwood products for 2-(2-phenylethyl)chromones using direct analysis in real time time-of-flight mass spectrometry. Rapid Commun. Mass Spectrom. 2012, 26, 2649-2656. 
3. Liu, Y.; Chen, H.; Yang, Y.; Zhang, Z.; Wei, J.; Meng, H.; Chen, W.; Feng, J.; Gan, B.; Chen, X.; et al. Whole-tree agarwood-inducing technique: An efficient novel technique for producing high-quality agarwood in cultivated Aquilaria sinensis trees. Molecules 2013, 18, 3086-3106.

4. CITES. The Trade and Use of Agarwood in Taiwan, Province of China. Available online: $\mathrm{http}: / / \mathrm{www}$.cites.org/common/com/pc/15/X-PC15-07-Inf.pdf (accessed on 24 July 2013).

5. CITES. The Use and Trade of Agarwood in Japan. Available online: http://www.cites.org/ common/com/pc/15/X-PC15-06-Inf.pdf (accessed on 24 July 2013).

6. Hansen, E. The hidden history of scented wood. Saudi Aramco World 2000, 51, 2-13.

7. Soehartono, T.; Newton, A.C. Conservation and sustainable use of tropical trees in the genus Aquilaria I. Status and distribution in Indonesia. Biol. Conserv. 2000, 96, 83-94.

8. Zhang, L.; Brockelman, W.Y.; Allen, M.A. Matrix analysis to evaluate sustainability: The tropical tree Aquilaria crassna, a heavily poached source of agarwood. Biol. Conserv. 2008, 141, 1676-1686.

9. IUCN. 2013 IUCN Red List of Threatened Species. Version 2013.1. Available online: http://www.iucnredlist.org (accessed on 24 July 2013).

10. Yang, D.L.; Mei, W.L.; Zeng, Y.B.; Guo, Z.K.; Zhao, Y.X.; Wang, H.; Zuo, W.J.; Dong, W.H.; Wang, Q.H.; Dai, H.F. 2-(2-Phenylethyl)chromone derivatives in Chinese agarwood "Qi-Nan" from Aquilaria senensis. Planta Med. 2013,79,1329-1334.

11. Dai, H.F.; Liu, J.; Zeng, Y.B.; Han, Z.; Wang, H.; Mei, W.L. A new 2-(2-phenylethyl)chromone from Chinese eaglewood. Molecules 2009, 14, 5165-5168.

12. Dai, H.F.; Liu, J.; Han, Z.; Zeng, Y.B.; Wang, H.; Mei, W.L. Two new 2-(2-phenylethyl)chromones from Chinese eaglewood. J. Asian Nat. Prod. Res. 2010, 12, 134-137.

13. Mei, W.L.; Liu, J.; Li, X.N.; Dai, H.F. Study on the chemical constituents from Chinese eaglewood in Hainan. J. Trop. Subtrop. Bot. 2010, 18, 573-576.

14. Yamagata, E.; Yoneda, K. Pharmacognostical studies on the crude drug of agarwood (VI): On “Kanankoh". Shoyakugaku Zasshi 1987, 41, 142-146.

15. Ishihara M; Tsuneya T; Uneyama K. Components of the volatile concentrate of agarwood. J. Essent. Oil Res. 1993, 5, 283-289.

16. Lin, F.; Dai, H.F.; Wang, H.; Mei, W.L. GC-MS analysis of the chemical constituents of essential oils from two kinds of Chinese eaglewood produced by artificial fungus inoculation. Lishizhen Med. Mater. Med. Res. 2010, 21, 1901-1902.

17. Tajuddin, S.N.; Yusoff, M.M. Chemical composition of volatile oils of Aquilaria malaccensis (Thymelaeaceae) from Malaysia. Nat. Prod. Commun. 2010, 5, 1965-1968.

18. Yang, J.S.; Wang, Y.L.; Su, Y.L. Studies on the chemical constituents of Aquilaria sinensis (Lour.) Gilg. IV. Isolation and characterization of 2-(2-phenylethyl)chromone derivatives. Acta Pharm. Sin. 1989, 24, 678-683.

19. Konishi, T.; Konoshima, T.; Shimada, Y.; Kiyosawa, S. Six new 2-(2-phenylethyl)chromones from Agarwood. Chem. Pharm. Bull. 2002, 50, 419-422.

20. Liu, X.; Zhang, B.F.; Yang, L.; Chou, G.X.; Wang, Z.T. Two new chromones and a new flavone glycoside from Imperata cylindrica. Chin. J. Nat. Med. 2013, 11, 77-80.

21. Alkhathlan, H.Z.; Al-Hazimi, H.M.; Al-Dhalaan, F.S.; Mousa, A.A. Three 2-(2-phenylethyl) chromones and two terpenes from agarwood. Nat. Prod. Res. 2005, 19, 367-372. 
22. Nakanishi, T.; Inada, A.; Nishi, M.; Yamagata, E.; Yoneda, K. A new and a known derivatives of 2-(2-phenylethyl)chromone from a kind of agarwood ("Kanankoh," in Japanese) originating from Aquilaria Agallocha J. Nat. Prod. 1986, 49, 1106-1108.

23. Yang, J.S.; Wang, Y.L.; Su, Y.L. Studies on the chemical constituents of Aquilaria sinensis (Lour.) Gilg. V. Isolation and characterization of three 2-(2-phenylethyl)chromone derivatives. Acta Pharm. Sin. 1990, 25, 186-190.

24. Yang, L.; Qiao, L.R.; Xie, D.; Yuan, Y.H.; Chen, N.H.; Dai, J.G.; Guo, S.X. 2-(2-Phenylethyl)chromones from Chinese eaglewood. Phytochemistry 2012, 76, 92-97.

25. Chen, D.; Xu, Z.R.; Chai, X.Y.; Zeng, K.W.; Jia, Y.X.; Bi, D.; Ma, Z.Z.; Tu, P.F. Nine 2-(2-phenylethyl)chromone derivatives from the resinous wood of Aquilaria sinensis and their inhibition of LPS-Induced NO production in RAW 264.7 Cells. Eur. J. Org. Chem. 2012, 2012, 5389-5397.

26. Gao, Y.H.; Liu, J.M.; Xu, H.H. Study on the structure of 2-(2-phenylethyl)chromone derivatives from Aquilaria sinensis. Chin. J. Org. Chem. 2005, 25 (Suppl.), 125.

27. Toru, Y.; Michiho, I.; Fumiyuki, K.; Gisho, H.; Yasuo, S. Four new 2-(2-phenylethyl)chromone derivatives from withered wood of Aquilaria sinensis. Chem. Pharm. Bull. 2003, 51, 560-564.

28. Wu, B.; Kwon, S.W.; Hwang, G.S.; Park, J.H. Eight new 2-(2-phenylethyl)chromone (=2-(2-Phenylethyl)-4H-1-benzopyran-4-one) derivatives from Aquilaria malaccensis agarwood. Helv. Chim. Acta 2012, 95, 1657-1665.

29. Chen, H.Q.; Wei, J.H.; Yang, J.S.; Zhang, Z.; Yang, Y.; Gao, Z.H.; Sui, C.; Gong, B. Chemical constituents of agarwood originating from the endemic genus Aquilaria plants. Chem. Biodivers. 2012, 9, 236-250.

30. Wu, B.; Lee, J.G.; Lim, C.J.; Jia, S.D.; Kwon, S.W.; Hwang, G.S.; Park, J.H. Sesquiterpenoids and 2-(2-phenylethyl)-4H-chromen-4-one (=2-(2-Phenylethyl)-4H-1-benzopyran-4-one) derivatives from Aquilaria malaccensis agarwood. Helv. Chim. Acta 2012, 95, 636-642.

31. Gao, Y.H.; Liu, J.M.; Lu, H.X.; Wei, Z.X. Two new 2-(2-phenylethyl)chromen-4-ones from Aquilaria sinensis (Lour.) Gilg. Helv. Chim. Acta 2012, 95, 951-954.

32. Wang, T.; Li, L.F.; Zhang, K.; Zhang, W.Y.; Pei, Y.H. New 2-(2-phenylethyl)chromones from Bothriochloa ischaemum. J. Asian Nat. Prod. Res. 2001, 3, 145-149.

33. Yoon, J.S.; Lee, M.K.; Sung, S.H.; Kim, Y.C. Neuroprotective 2-(2-phenylethyl)chromones of Imperata cylindrica. J. Nat. Prod. 2006, 69, 290-291.

34. Ibrahim, S.R. New 2-(2-phenylethyl)chromone derivatives from the seeds of Cucumis melo L var. reticulatus. Nat. Prod. Commun. 2010, 5, 403-406.

35. Yoneda, K.; Yamagata, E.; Nakanishi, T.; Nagashima, T.; Kawasaki, I.; Yoshida, T.; Mori, H.; Miura, I. Sesquiterpenoids in two different kinds of agarwood. Phytochemistry 1984, 23, 2068-2069.

36. Meier, M.; Kohlenberg, B.; Braun, N.A. Isolation of anisyl acetone from agarwood oil. J. Essent. Oil Res. 2003, 15, 54-56.

37. Mei, W.L.; Zeng, Y.B.; Wu, J.; Dai, H.F. Chemical composition and anti-MRSA activity of the essential oil from Chinese eaglewood. J. Chin. Pharm. Sci. 2008, 17, 225-229.

Sample Availability: Samples of the the agarwood are available from the authors.

(C) 2013 by the authors; licensee MDPI, Basel, Switzerland. This article is an open access article distributed under the terms and conditions of the Creative Commons Attribution license (http://creativecommons.org/licenses/by/3.0/). 